\title{
EPIGRAFÍA DE CARTHAGO NOVA (CARTAGENA, ESPAÑA): APORTACIONES METODOLÓGICAS AL ESTUDIO TÉCNICO Y ESPACIAL
}

\author{
EPIGRAPHY OF CARTHAGO NOVA (CARTAGENA, SPAIN): METODOLOGICAL CONTRIBUTIONS TO \\ TECHNICAL AND SPATIAL STUDY
}

\author{
MIGUEL MARTÍNEZ SÁNCHEZ \\ Universidad de Murcia \\ miguel.martinez.sanchez@hotmail.com \\ http://orcid.org/0000-0003-2180-9071
}

Recepción: 03-05-2017

Aceptación: 03/07/2017

\section{Resumen}

Se presentan los resultados obtenidos tras la actualización de los datos sobre el patrimonio epigráfico romano de la ciudad de Cartagena (España), digitalizados en una base de datos y representados en mapas para un mejor estudio arqueológico. Mediante el traslado a ordenador de toda la información bibliográfica y catalográfica existente hasta 2015 , se ha podido crear una hoja de cálculo de manejo más cómodo para el trabajo de investigación. Por otro lado, mediante software GIS se ha representado espacialmente la localización de las piezas en un formato que permita estudiar la distribución espacial y trasladar los datos a software vectorial. Mediante este sistema de trabajo se ha pretendido crear un archivo consultable y actualizable en línea que facilite el trabajo arqueológico de los profesionales y el acceso a la cultura del público no especializado. También se plantea la posible creación de una página web donde se pueda difundir la información de estos epígrafes al público, a modo de complemento para los impulsores del turismo cultural y para acercar al patrimonio cultural cartagenero a todos los interesados en la epigrafía de época romana.

Palabras clave. Epigrafía; Carthago Nova; Cartagena; SIG; base de datos; mapas; estadística.

\begin{abstract}
This article presents the results obtained after the update of the data about epigraphic Roman heritage from the city of Cartagena, Spain, which have been digitalized in a database and represented in maps for a more useful archaeological study. Thanks to the transfer to computer of all the bibliographic and catalogue information collected until 2015, it has been possible to create a friendlier spreadsheet for researchers. On the other hand, by using GIS (Geographical Information System) software, the spatial location of the inscriptions has been pictured in a digital format able to ease the spatial study and capable to transfer the data to a CAD format. Because of this workflow, we have obtained a searchable and updateable online archive, so that it reaches professionals as well as non-specialized readers. There is also the possibility to create a website were results are broadcasted online, serving as a contribution to touristic information and at the same time bringing closer the Roman heritage of Cartagena to everybody.
\end{abstract}

Key words. Epigraphy; Carthago Nova; Cartagena; GIS; database; maps; statistics. 


\section{INTRODUCCIÓN}

Durante las últimas décadas, la ciudad de Cartagena se ha convertido en uno de los centros urbanos de mayor actividad arqueológica del sureste peninsular. Gracias a las sucesivas excavaciones y musealizaciones en el casco histórico, se ha transformado el aspecto de la ciudad e incorporado el turismo cultural a su oferta como una pieza fundamental. Actualmente contamos con una creciente cantidad de investigaciones históricas, gracias a las cuales conocemos mejor cómo se desarrollaron las fases de la ciudad durante su fundación púnica y posterior ocupación romana, época en la cual se desarrolló como centro político-económico hispano de la Antigüedad ( $c f$. Ramallo y Ruiz, 1998; AA. VV., 2004; Noguera y Madrid, 2009; Ramallo, 2011; Noguera, Cánovas, Madrid y Martínez, 2016).

Uno de los aspectos que convierten a Cartagena en una ciudad romana de gran importancia es su epigrafía, la cual fue recopilada con metodología moderna por primera vez en 1997 por los doctores Abascal y Ramallo en el monográfico titulado «La ciudad de Carthago Nova: la documentación epigráfica». Esta obra supuso un antes y un después para el estudio de estos materiales de época antigua en la ciudad, gracias a que tuvo en cuenta la información tanto de fuentes antiguas como de estudios recientes. Tras 20 años de la publicación de dicha obra, el número de inscripciones antiguas que conocemos hoy ha crecido paulatinamente, dando lugar a una gran producción científica en los últimos años ( $c f$. Ramallo, Fernández, Madrid y Ruiz, 2008; Ramallo, Murcia y Vizcaíno, 2010; Ramallo, 2010-2011; Abascal, Noguera y Madrid, 2012; Ramallo, Ruiz, Murcia y Guillermo, 2013b; Noguera y Madrid, 2014; González, Noguera, Belmonte, Rodríguez, Ruiz, Madrid, Zamora y Bonnet, 2015; Ramallo, 2015; Fernández, Ramallo y Suarez, 2016; Noguera, Cánovas, Madrid y Martínez, 2016; Abascal, Ramallo y Schmidt, 2017). Debido a este hecho, consideramos necesario realizar una puesta al día que incluya la información publicada desde 1997 hasta 2016, de modo que actualice el número de piezas y transforme la información escrita a una base de datos que resulte más cómoda para el trabajo en comparación a otros medios consultables en línea como Hispania Epigraphica o Clauss-Slaby, siendo esta última una herramienta de gran importancia para la búsqueda de paralelos arqueológicos a nivel internacional.

A lo largo de este trabajo, se ha tenido en cuenta la necesidad de poder volcar la información existente sobre los epígrafes de Cartagena en mapas sobre software SIG, cruzando los datos técnicos con los espaciales para comprender mejor su distribución en el área urbana de la antigua Carthago Nova. Para la representación espacial de estas piezas se ha acudido al software libre Quantum GIS. Para la realización de la base de datos se ha utilizado el software Microsoft Office Access, el cual ha permitido crear una tabla donde se recojan en campos y entradas toda la información de las piezas. Con el objetivo de garantizar la mayor comodidad en la consulta de los epígrafes inventariados citados en este texto, se ha albergado la información de la base de datos y los mapas en un servicio de alojamiento de archivos online donde puedan ser consultados de manera abierta y libre. Enlace: http://bit.ly/2n53OAV

\section{HISTORIOGRAFÍA DE LA EPIGRAFÍA DE CARTAGENA}

La epigrafía romana de Cartagena ha sido uno de los temas de la arqueología clásica local mejor estudiados gracias a las sucesivas visitas de eruditos y aficionados de distintas épocas, movidos por la búsqueda de aquella «urbs opulentissima» mencionada en las fuentes antiguas (Livio, XXVI, 48). Conforme la ciudad creció, salieron a la luz multitud de piezas, muchas de las cuales no se han conservado hasta la actualidad, bien por su destrucción o por haber desaparecido a causa del comercio de antigüedades. Gracias a los escritos, hoy contamos con documentación sobre estas inscripciones que nos permite reconstruir parcialmente cómo fueron estas piezas arqueológicas, a pesar de la falta de metodología en aquella época (Abascal y Ramallo, 1997: 9) y la manipulación explícita de algunos textos y traducciones para engrandecer la historia local de Cartagena (Ramallo, 2011: 20).

La mayoría de datos antiguos sobre la epigrafía de Cartagena que han llegado hasta hoy los conocemos gracias a viajeros y eruditos como fray Jerónimo Hurtado, Abraham de Bibran, Hermosillo y Parrilla, Espinalt, Lozan, Ceán Bermúdez o Francisco Cascales (Abascal y Ramallo, 1997: 19). A partir del siglo XVIII encontramos a multitud de personajes importantes en materia de epigrafía local, caso de Fulgencio Cerezuela, Francisco Ximénez, Nicolás Montanaro o Ascensio Morales. Hacia mitad de este siglo tenemos trabajos como los de Leandro Soler y Vargas Ponce, aunque sin duda el autor que más importancia ha tenido ha sido Antonio Valcárcel Pío de Saboya, Conde de Lumiares. En su obra "Inscripciones de Carthago Nova, hoy Cartagena, en el Reyno de Murcia», escrita en 1796 (Abascal, Noguera y Navarro, 2002; Abascal, Die y Cebrián, 2009), se encuentran recogidas un total de 70 inscripciones, descritas con una gran delicadeza e incluso dibujadas por el autor. Muchas de las inscripciones ya estaban desaparecidas cuando se escribió el libro y sólo las conocemos gracias a este autor, de ahí su gran importancia como fuente.

Durante el siglo XIX aparecen los grandes corpora epigráficos. Cabe destacar la visita de Emil Hübner a Cartagena en 1860 en sus trabajos para redactar el volumen II del CIL que se publicaría 9 años después. En esa misma época se publicaron los inventarios del Museo Arqueológico Nacional de Juan de Dios de la Rada. En este siglo se perdieron muchas inscripciones 
debido a las demoliciones de la Casa de los Cuatro Santos, de algunos tramos del Castillo de la Concepción (1868) y finalmente el edificio antiguo del ayuntamiento (1894), este último recordado como un hecho nefasto por la gran cantidad de piezas destruidas (Abascal y Ramallo, 1997: 21).

A partir del siglo XX tenemos a figuras como Diego Jiménez de Cisneros o Manuel González Simancas, los cuales inventariaron las piezas conservadas a comienzos de la centuria. Tras la Guerra Civil, continuaron los trabajos Antonio Beltrán y Pedro San Martín Moro. Uno de los mayores hitos en estas décadas fue la construcción del Museo Arqueológico Municipal de Cartagena en 1967, localizado sobre la necrópolis de San Antón, al norte de la ciudad. La actividad arqueológica de Cartagena se multiplicó a partir de los años 80 , dando lugar a la declaración del centro de la ciudad como casco antiguo (Ramallo, Ruiz, Murcia y Guillermo, 2013: 12). Destacan enormemente las investigaciones surgidas en las excavaciones del teatro romano, dirigido por Sebastián Ramallo y Elena Ruiz, así como el cerro del Molinete, dirigido por José Miguel Noguera y María José Madrid, ambos proyectos con un impacto muy positivo para la ciudad. El panorama actual de la ciudad tiene como objetivos para los próximos años las excavaciones del sector oriental del Molinete, el anfiteatro, el cerro de Monte Sacro y posiblemente el pórtico del teatro romano. También se han llevado a cabo investigaciones en torno al puerto de la ciudad, como la recientemente leída tesis doctoral de Felipe Cerezo (a 19 de octubre de 2016), trabajo que ayudará enormemente a conocer la forma antigua de Carthago Nova junto a las investigaciones del proyecto Arqueotopos, actualmente dirigido por el profesor Dr. Sebastián Ramallo.

\section{ANALISIS TÉCNICO}

Durante el proceso de digitalización de los datos, se ha trasladado la información publicada en papel a una tabla compuesta por las siguientes columnas para cada uno de los rasgos de las inscripciones: número de inventario, fecha del hallazgo, lugar del hallazgo, contenido del texto, desarrollo de las reconstrucciones, tipo de texto, soporte, tipo de soporte, material, periodo, época, tipo de letra, tipo de interpunción, alto, ancho, grosor, latitud, longitud, cantidad de fragmentos, catálogos donde aparecen, hipervínculo al epígrafe, ID en Clauss-Slaby, bibliografía y varios campos de sí/no (mujer, liberto, doble moldura, púnico, desaparecido, epígrafe griego y lugar original). En este trabajo se ha tenido en cuenta como cronología la aparecida en la publicación más actual para la fecha de 2016 de cada uno de los casos, consultable en sus respectivos artículos o libros.

Tras la recopilación de la información sobre la epigrafía de Cartagena publicada hasta el año 2016, se han encontrado un total de 334 inscripciones, 105 nuevas junto a las 229 recogidas hasta 1997 por los doctores Abascal y Ramallo, cifra cuyo orden y numeración se ha respetado en la nueva base de datos. El incremento se debe principalmente a los trabajos arqueológicos en el teatro romano y el cerro del Molinete, dos principales focos de investigación en la ciudad durante las últimas dos décadas. Estas dos excavaciones no han concluido del todo, sino que se encuentran en activo actualmente y siguen aportando más información año tras año. Por otro lado, los trabajos realizados en diversos solares del casco urbano han supuesto la otra gran aportación de los últimos 20 años a nuestro conocimiento de la epigrafía local en Carthago Nova.

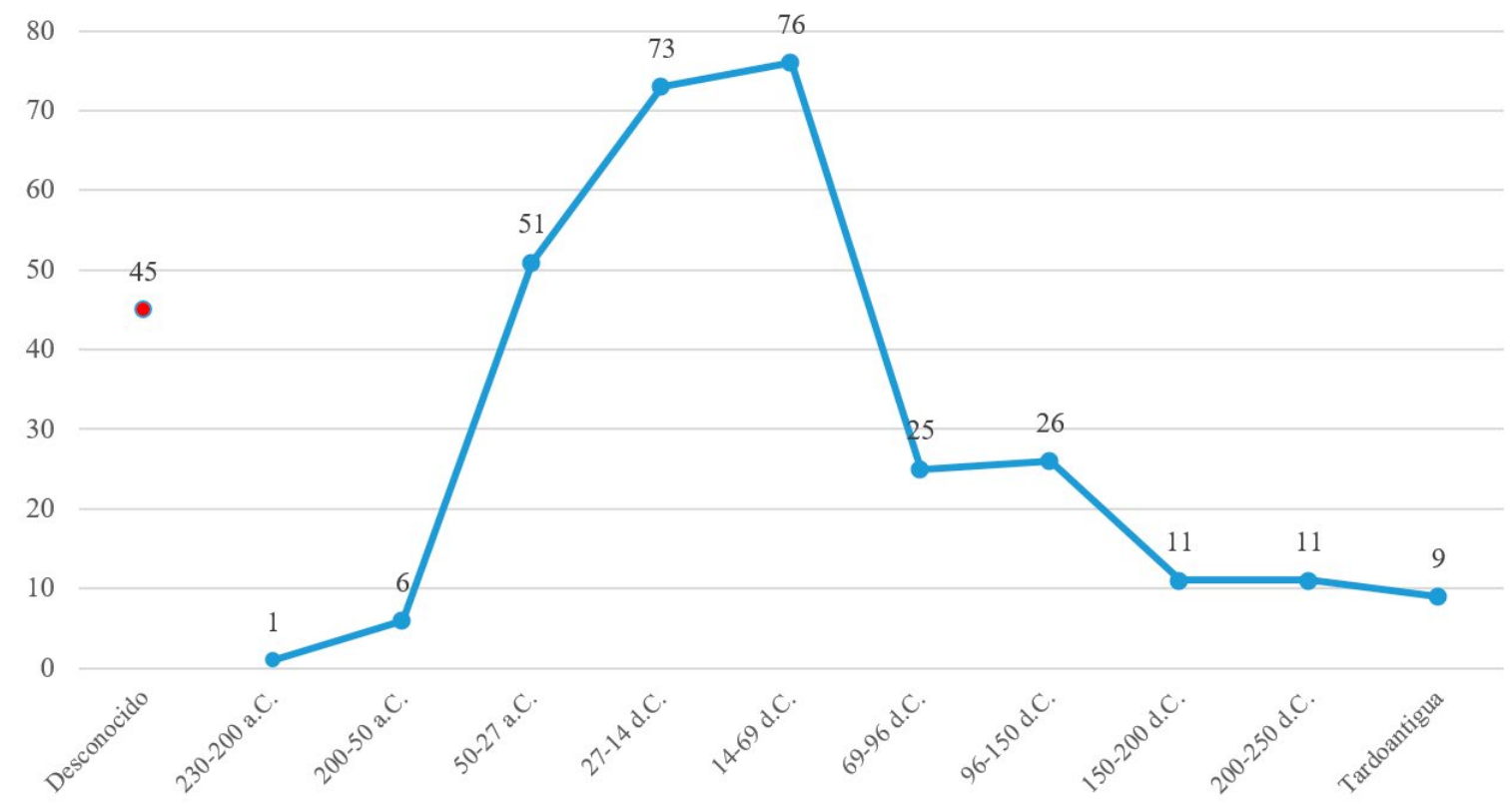

Figura 1: Cronología de los epígrafes de Carthago Nova por periodo. 

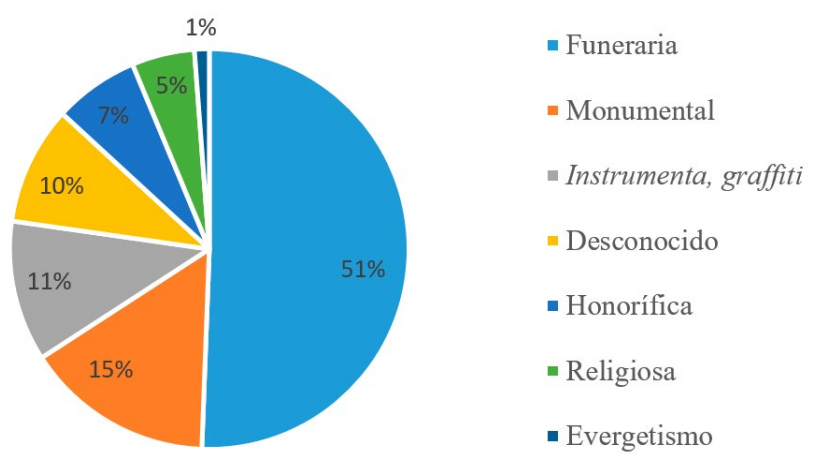

Figura 2: Distribución de epígrafes por tipo de texto.

El primer aspecto que llama la atención en la base de datos ha sido la cronología (Fig. 1). La fecha asignada para los epígrafes de la ciudad muestra una gran concentración durante el final del siglo I a.C. y la primera mitad de la siguiente centuria, coincidiendo con los últimos años de la etapa republicana y descendiendo en número a partir del final de la dinastía Flavia. Apenas se han conservado inscripciones anteriores al siglo I a.C. y posteriores al II d.C. En el registro se observa una gran concentración de inscripciones en época tardorrepublicana, algo poco común en los yacimientos romanos del litoral mediterráneo. Esta precoz profusión del fenómeno de la epigrafía convierte a la ciudad en la mayor colección de epigrafía republicana de la Península Ibérica (Díaz, 2008: 22; Abascal, Ramallo y Schmidt, 2017: 72). Por el contrario, no conocemos la cronología de 45 piezas, principalmente por haber desaparecido o

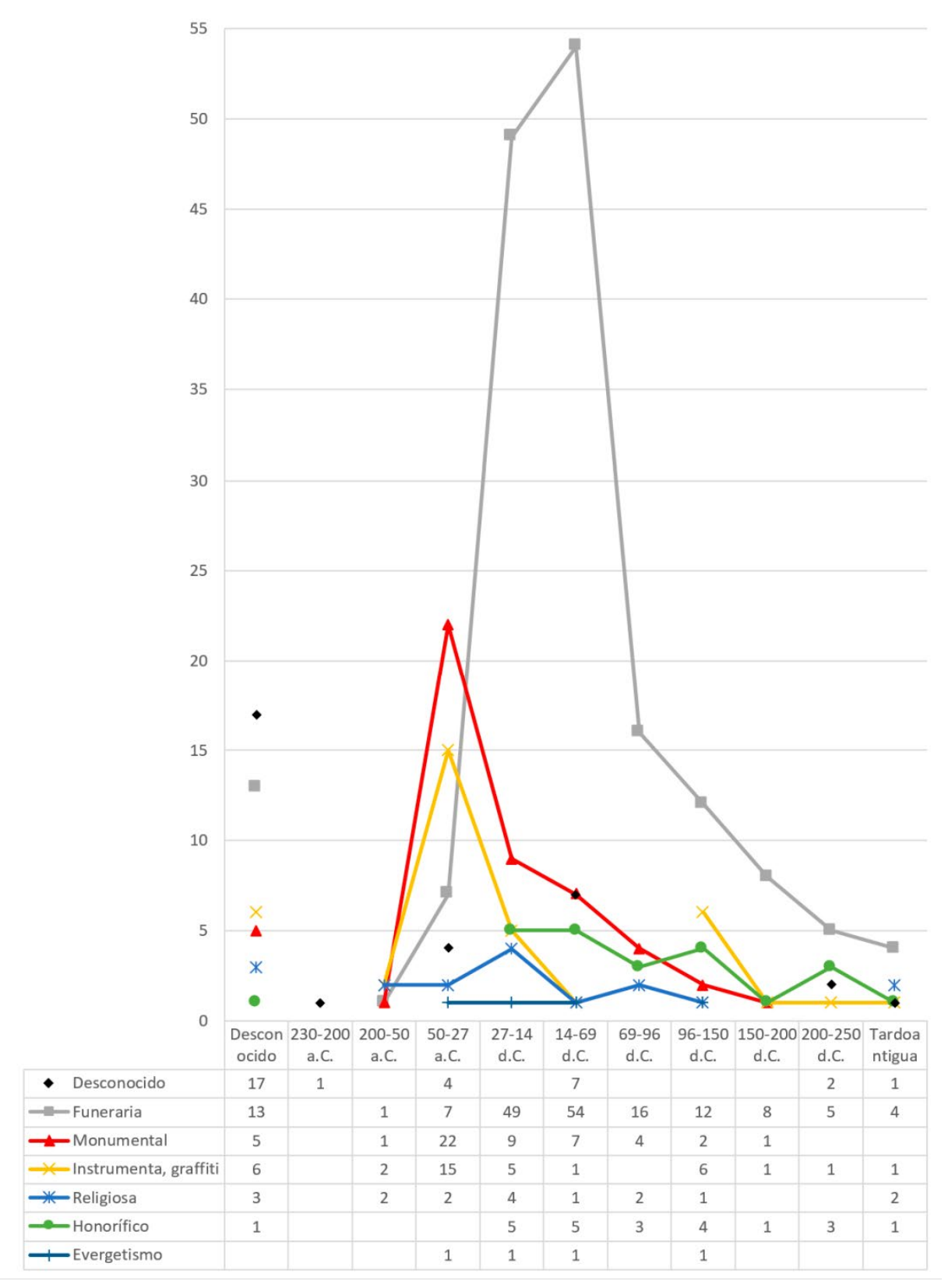

Figura 3: Tipos de texto usado en los epígrafes por periodo. 
encontrarse muy dañadas. Tampoco conocemos el lugar de aparición de 29 piezas, principalmente por tratarse de piezas que se encontraron de manera fortuita o bien fueron estudiadas sin tener en cuenta su contexto arqueológico.

La distribución de los epígrafes por tipo de texto (Fig. 2) nos muestra un claro protagonismo de la epigrafía funeraria (169 de las 334, el 50,6\%). Le siguen las piezas monumentales (51), los instrumenta o graffiti (38), las honoríficas (23), religiosas (17) y finalmente evergéticas (4). Hay un total de 32 inscripciones en las cuales no se ha podido determinar el tipo. Resulta lógico el protagonismo de las inscripciones funerarias, ya que suelen ser el destino más recurrente de los epígrafes encontrados en yacimientos arqueológicos de época romana, al tratarse de piezas utilizadas por gran parte de la sociedad como parte de los rituales funerarios de la época. Si atendemos a la distribución temporal de las mismas, se observa un gran repunte de epígrafes funerarios de época augustea y julio-claudia mientras que los epígrafes monumentales y las marcas realizadas sobre objetos o inscripciones murales muestran una aparición mucho mayor en época tardorrepublicana (Fig. 3).

El tipo de material más utilizado (Fig. 4) es el pétreo, presente en 298 casos $(89 \%$ del total) frente a los 30 sobre metal, 5 mediante pigmentos sobre paredes, todos ellos encontrados en el cerro del Molinete, y un solo ejemplo sobre hueso, el cual resulta ser el más antiguo de toda la colección (García y Giménez, 2007: 105-122; Hoz, 2014: 292). En el caso de los materiales metálicos, 26 piezas están realizadas sobre plomo, principalmente anclas o lingotes, mientras que 4 de ellas se han realizado en bronce. De los epígrafes sobre piedra, los materiales más usados son la caliza gris local o micrítica (134) y el mármol blanco (43). Respecto al protagonismo de la caliza gris local, estamos ante el uso de un material de fácil acceso y más económico, ya que el resto de materiales requerían su importación y trabajado específico, lo cual encarecía todo el proceso. En este sentido, destaca la tendencia al uso de caliza micrítica para inscripciones funerarias (93 de 169, un 55\%) y monumentales ( 24 de 51, un $47 \%$ ), con un gran crecimiento de su uso en época augustea (Fig. 5).

Todavía se conoce poco sobre el sistema de explotación local de materias primas para la epigrafía, aunque contamos con algunos trabajos sobre las canteras de la Sierra Minera de Cartagena ( $c f$. Antolinos, 2005; Antolinos y Soler, 2007; Antolinos, 2008; Díaz, 2009; Antolinos, Fabre y Rico, 2010; Antolinos, Noguera y Soler, 2010; Díaz y Antolinos, 2013) y la marmorización de la ciudad en época imperial ( $c f$. Soler, 2005a; 2005b; 2008; Soler, Antolinos, Noguera y Alías, 2012: 289; Noguera y Madrid, 2013). A nivel de inscripciones sólo contamos con un testimonio que haga mención explícita de un faber lapidarius, de cognomen aparentemente oriental, «Samalo» (Abascal y Rama1lo, 1997: $\mathrm{n}^{\circ}$ 153). Esta inscripción funeraria de época

\begin{tabular}{|l|c|}
\hline \multicolumn{1}{|c|}{ Material } & Total \\
\hline Caliza gris local & 134 \\
\hline Desconocido & 66 \\
\hline Mármol blanco & 43 \\
\hline Plomo & 26 \\
\hline Mármol del Cabezo Gordo & 20 \\
\hline Travertino rojo & 10 \\
\hline Mármol crema & 10 \\
\hline Mármol gris de Hipona & 7 \\
\hline Pigmento & 5 \\
\hline Mármol de veta roja & 4 \\
\hline Bronce & 4 \\
\hline Serpentina gris azulada & 3 \\
\hline Esparita melada & 1 \\
\hline Brecha Coralina & 1 \\
\hline
\end{tabular}

Figura 4: Materiales más utilizados.

augustea es un unicum en todo el registro, sumado al hecho de que los datos que tenemos sobre la producción de epígrafes en talleres locales son pocos. Actualmente no tenemos suficiente información sobre el sistema de explotación de canteras, aunque el auge de la minería de galena argentífera pudo ser un aliciente para abaratar la extracción de estos materiales locales o comunicar mejor Carthago Nova con explotaciones cercanas como las de travertino rojo de la Almagra (Mula) o el mármol del Cabezo Gordo (Torre Pacheco), ambos muy presentes en el programa constructivo del área del foro y el teatro a finales del siglo I a.C. (Soler, 2005a: 38).

En cuanto al tipo de soporte sobre el cual se realizaban las inscripciones, destaca claramente la placa, seguida de los lingotes para las marcas sobre plomo (Fig.6). Los pedestales conservados pertenecen en gran número al programa decorativo del foro, en el cual se usaron pedestales honoríficos como parte del proceso de monumentalización de la ciudad, formando parte de un parapeto con 12 antae (Noguera, Soler, Madrid y Vizcaíno, 2009: 235), muchos de los cuales acabaron descontextualizados en época tardoantigua debido al sucesivo expolio de materiales del área foral (Vizcaíno, 2002). Al igual que ocurre con los tipos de materiales elegidos, encontramos algunas inscripciones de las cuales no alcanzamos a distinguir su tipo de soporte del todo (42 de 334, un $12,57 \%$ ), bien porque han desaparecido, por encontrarse muy dañadas o bien por no aparecer información suficiente en las publicaciones de dichas piezas arqueológicas.

Las interpunciones de las inscripciones de Carthago Nova nos sirven para dotarlas de cronología $\mathrm{y}$ distinguirlas, ya que en muchas ocasiones parecen responder a un patrón de modas importadas de la Península Itálica. Así, la distribución cronológica refleja cómo hay un mayor número de interpunciones 


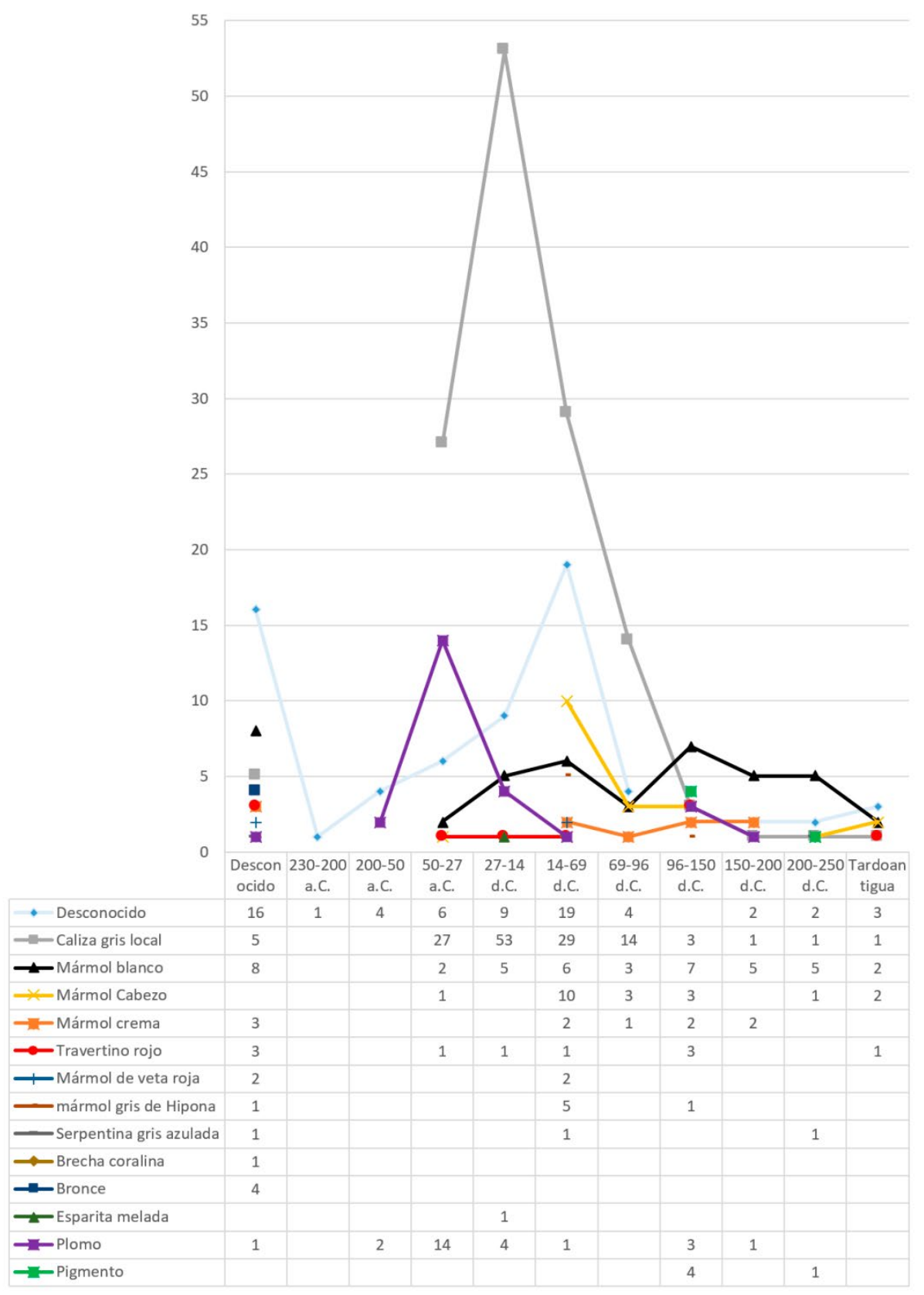

Figura 5: Materiales usados en los epígrafes por periodo.

cuadradas en el periodo cesariano (26 de 51) mientras que destacan las de tipo triangular (normal o invertido) desde época augustea (37 de 73) y hasta época flavia (Fig. 7). En ambos casos ocupan la mitad del total computado para la época, destacando sobre las demás si tenemos en cuenta que hay un porcentaje del total del cual desconocemos su interpunción, especialmente en la primera mitad del siglo I d.C. Podemos observar una cierta correlación entre el tipo de interpunción y el texto para el que ha sido usada para algunos ejemplos. Por un lado, las triangulares son eminentemente funerarias $(50$ de 71,56 de 87 si sumamos las triangulares invertidas) mientras que las cuadradas muestran una distribución mayor entre piezas funerarias (17 de 58), instrumenta (17) y monumentales (12), entre otras. En el caso de las interpunciones circulares, 8 de las 10 que se han recogido son de tipo funerario. De modo similar ocurre en las 14 interpunciones en forma de flecha, todas usadas en inscripciones funerarias. Por el contrario, de las 334 piezas, nos falta información sobre el tipo de interpunción para 156, lo cual representa el 46,7\% del total. En el caso de los materiales sobre los que se han realizado tan sólo cabe mencionar la gran la correlación que hay entre el uso de la caliza gris local con piezas de interpunciones triangulares (61 de 87), y circulares ( 8 de 10), hecho que tiene relación con el alto número de piezas de este material durante el ya citado arco cronológico de finales del siglo I a.C. y comienzos del siguiente. 


\begin{tabular}{|c|c|}
\hline Tipo de Soporte & Total \\
\hline Placa & 177 \\
\hline Desconocido & 42 \\
\hline Lingote & 23 \\
\hline Pedestal & 20 \\
\hline Bloque & 19 \\
\hline Bloque paralelepipédico & 11 \\
\hline Ara & 6 \\
\hline Mosaico & 6 \\
\hline Grafito & 5 \\
\hline Anillo & 4 \\
\hline Columna & 4 \\
\hline Monumental con litterae aureae & 4 \\
\hline Ancla & 3 \\
\hline Dintel & 3 \\
\hline Cipo & 2 \\
\hline Estela & 2 \\
\hline Lápida & 2 \\
\hline Friso & 1 \\
\hline Romana & 1 \\
\hline
\end{tabular}

Figura 6: Tipos de soporte más utilizados.

\section{ANÁLISIS SOCIAL DE LAS INSCRIPCIONES}

La aparición de ciertas familias en los textos de las inscripciones nos ayuda a comprender y conocer mejor la presencia de gentes relacionadas con el comercio y la vida política de Carthago Nova como ciudad romana. En total, se han recogido 108 tipos diferentes, una cantidad de nomina muy variada que abarca desde época republicana hasta la Tardoantigüedad (Fig. 9). De todas estas gentes se ha realizado una selección de los principales gentilicios con mayor presencia en el registro arqueológico (Fig. 8). Destaca especialmente la gens Numisia, con un total de 11 inscripciones donde se menciona dicho nomen, además de una distribución temporal constante desde época tardorrepublicana hasta época trajanea. Esta familia muestra un arraigo sin igual en la ciudad, por lo que podemos estar hablando de una de las más importantes en la zona, de acuerdo al registro de epígrafes locales. Para indagar más a fondo en la información sobre gentes en la ciudad de Carthago Nova, contamos con la tesis doctoral de Adela Barreda, leída en 1998 y con un contenido mucho más profundo respecto a los gentilicios locales. También destaca el trabajo de Borja Díaz en materia de comercio minero relacionado con familias como los Pontilienii o los Numisii (2009: 143 et ss.).

Al igual que ocurre con la mención a ciertas familias locales, el contenido de los epígrafes nos ayuda a localizar algunos datos sociales de interés para el estudio de la presencia de ciertos miembros de la sociedad romana. Los libertos son uno de ellos, ya que su condición aparece mencionada en los formularios de los epígrafes. Hemos recogido un total de 75 inscripciones con libertos, de las cuales 70 son funerarias (92\%), 2 monumentales y un caso para inscripciones religiosas e instrumenta. Su mayor presencia en este tipo de epígrafes resulta lógica puesto que su condición jurídica les impedía ocupar cargos públicos en las ciudades, excepción hecha del sevirato augustal. Estas 75 inscripciones representan el 22,5\% del total, una cifra destacable dentro de todo el cómputo (Fig. 10). De nuevo volvemos a observar una gran concentración de inscripciones fechadas desde el principado de Augusto hasta la dinastía Flavia, muchas de ellas

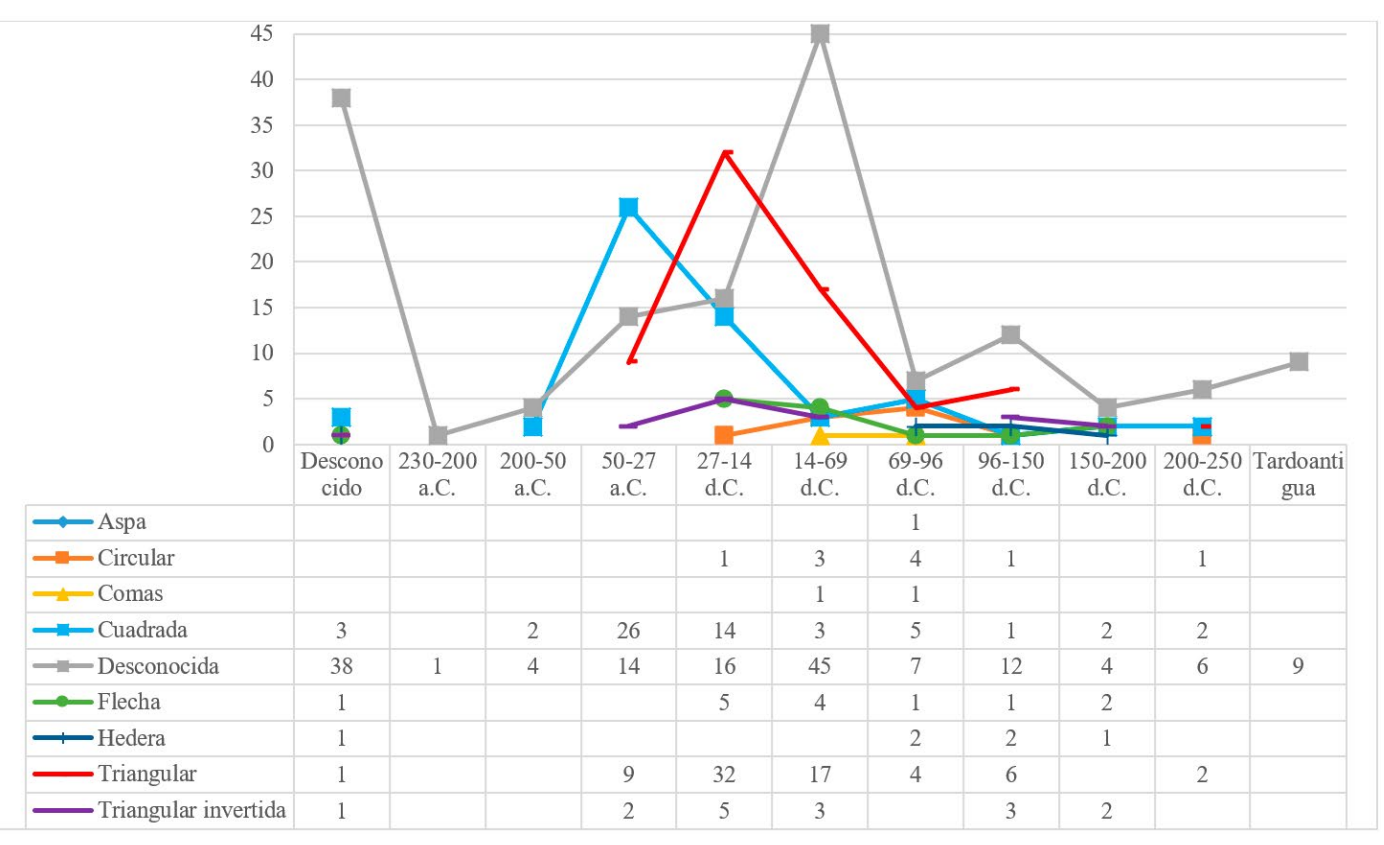

Figura 7: Tipos de interpunción utilizadas en las inscripciones por periodo. 


\begin{tabular}{|c|c|c|c|c|c|c|c|}
\hline & TOTAL & 200-50 a.C. & 50-27 a.C. & 27-14 d.C. & 14-69 d.C. & 69-96 d.C. & 96-150 d.C. \\
\hline Aemilius & 5 & & 1 & & 2 & 2 & \\
\hline Caesius & 4 & & & 1 & & & 3 \\
\hline Clodius & 5 & & 1 & 3 & & 1 & \\
\hline Cornelius & 5 & & 3 & & 1 & & 1 \\
\hline Laetilius & 6 & & 1 & 1 & 4 & & \\
\hline Numisius & 11 & 1 & 3 & 1 & 2 & 1 & 3 \\
\hline Pompeius & 4 & & 1 & & 1 & 2 & \\
\hline Pontilienus & 5 & 2 & & & & 3 & \\
\hline Vergilius & 6 & & & 1 & 5 & & \\
\hline
\end{tabular}

Figura 8: Principales gentilicios en la epigrafía de Carthago Nova.

\begin{tabular}{|c|c|c|c|c|c|c|c|c|c|}
\hline NOMEN & 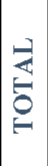 & 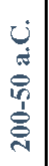 & 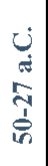 & 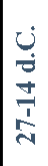 & $\begin{array}{l}0 \\
0 \\
+ \\
0 \\
0 \\
1 \\
\pm \\
-1\end{array}$ & 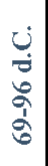 & 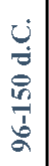 & 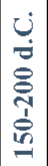 & 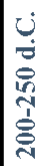 \\
\hline Aefolanus & 1 & & 1 & & & & & & \\
\hline Aelius & 2 & & & & & & & 2 & \\
\hline Aemilius & 5 & & 1 & & 2 & 2 & & & \\
\hline Agrius & 2 & & & & & & 2 & & \\
\hline Aleidius & 1 & & 1 & & & & & & \\
\hline Annius & 2 & & & & 1 & 1 & & & \\
\hline Antonia & 3 & & & 1 & 1 & & & & 1 \\
\hline Appuleius & 1 & & & & 1 & & & & \\
\hline Aquinus & 2 & 1 & & 1 & & & & & \\
\hline Argentaria & 1 & & & & 1 & & & & \\
\hline Attelius & 3 & & 1 & 1 & 1 & & & & \\
\hline Avius & 2 & & 2 & & & & & & \\
\hline Avitus & 1 & & & & & & & & 1 \\
\hline $\begin{array}{l}\text { Aurunculei } \\
\text { us }\end{array}$ & 2 & & 1 & 1 & & & & & \\
\hline Baebius & 1 & & 1 & & & & & & \\
\hline Bombia & 1 & & & 1 & & & & & \\
\hline Brossius & 1 & & & 1 & & & & & \\
\hline Brutius & 1 & & 1 & & & & & & \\
\hline Caedius & 1 & & & & 1 & & & & \\
\hline Caeicius & 1 & 1 & & & & & & & \\
\hline Caesernia & 1 & & & & 1 & & & & \\
\hline Caesius & 4 & & & 1 & & & 3 & & \\
\hline Calpurnius & 1 & & 1 & & & & & & \\
\hline Caprius & 1 & & & & & 1 & & & \\
\hline Cassius & 2 & & & & 2 & & & & \\
\hline Catius & 1 & & 1 & & & & & & \\
\hline Ceruius & 1 & 1 & & & & & & & \\
\hline Claudius & 3 & 1 & & 1 & & 1 & & & \\
\hline Clodius & 5 & & 1 & 3 & & 1 & & & \\
\hline Cornelius & 5 & & 3 & & 1 & & 1 & & \\
\hline Didius & 2 & & & & 1 & 1 & & & \\
\hline Fabius & 1 & & 1 & & & & & & \\
\hline Fabricius & 2 & & & 2 & & & & & \\
\hline
\end{tabular}

\begin{tabular}{|c|c|c|c|c|c|c|c|c|c|}
\hline NOMEN & 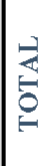 & 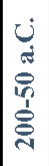 & 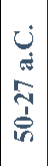 & 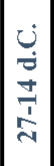 & 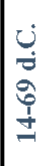 & 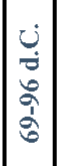 & 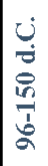 & 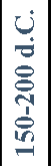 & 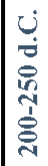 \\
\hline Fannius & 1 & & & & 1 & & & & \\
\hline Fufius & 2 & & & & 1 & 1 & & & \\
\hline Fuluinius & 2 & & & & 1 & & 1 & & \\
\hline Fuluius & 2 & & & 1 & & 1 & & & \\
\hline Furius & 2 & & & & 1 & 1 & & & \\
\hline Gratia & 2 & & & & & & & & 2 \\
\hline Geminius & 1 & & & & & & 1 & & \\
\hline Helvius & 1 & & & & & 1 & & & \\
\hline Herius & 1 & & & & & 1 & & & \\
\hline Insteius & 1 & & & 1 & & & & & \\
\hline Iulius & 3 & & 1 & 1 & 1 & & & & \\
\hline Iunius & 2 & & & 2 & & & & & \\
\hline Labicius & 3 & & & 3 & & & & & \\
\hline Laelius & 1 & & & & 1 & & & & \\
\hline Laetilius & 6 & & 1 & 1 & 4 & & & & \\
\hline Lamius & 1 & & & & & & 1 & & \\
\hline Licinius & 1 & & & & & 1 & & & \\
\hline Lollius & 1 & & & & 1 & & & & \\
\hline Lucius & 2 & & & 1 & 1 & & & & \\
\hline Lucretius & 2 & & & 2 & & & & & \\
\hline Lumnesia & 2 & 2 & & & & & & & \\
\hline Lusius & 1 & & & 1 & & & & & \\
\hline Maecius & 1 & & & 1 & & & & & \\
\hline Maestius & 1 & & & & & 1 & & & \\
\hline Magius & 1 & & & 1 & & & & & \\
\hline Manilius & 1 & & & & & & & 1 & \\
\hline Marius & 1 & & & & 1 & & & & \\
\hline Marcius & 2 & & & 1 & & 1 & & & \\
\hline Maticius & 1 & & & & & 1 & & & \\
\hline Memmia & 1 & & & & & & 1 & & \\
\hline Messius & 1 & & & 1 & & & & & \\
\hline Nosteius & 1 & & & 1 & & & & & \\
\hline Numisius & 11 & 1 & 3 & 1 & 2 & 1 & 3 & & \\
\hline
\end{tabular}




\begin{tabular}{|c|c|c|c|c|c|c|c|c|c|}
\hline NOMEN & 造 & 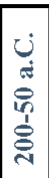 & 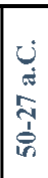 & 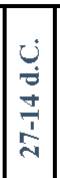 & 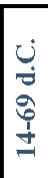 & 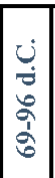 & 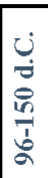 & 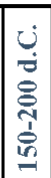 & 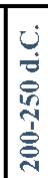 \\
\hline Octavia & 3 & & & 1 & & 2 & & & \\
\hline Ofelius & 1 & & & & 1 & & & & \\
\hline Oppius & 1 & & & & 1 & & & & \\
\hline Paquius & 2 & 1 & & 1 & & & & & \\
\hline Plotia & 3 & & & & 1 & 2 & & & \\
\hline Pompeius & 4 & & 1 & & 1 & 2 & & & \\
\hline Pomponius & 1 & & & & 1 & & & & \\
\hline Pontilienus & 5 & 2 & & & & 3 & & & \\
\hline Popilius & 1 & 1 & & & & & & & \\
\hline Postumius & 2 & & & 1 & & & & 1 & \\
\hline Prosius & 1 & & 1 & & & & & & \\
\hline Publicius & 1 & & & & & & & 1 & \\
\hline Puupius & 1 & & 1 & & & & & & \\
\hline Quintia & 1 & & & & & 1 & & & \\
\hline Raius & 1 & & & 1 & & & & & \\
\hline Saponius & 1 & & 1 & & & & & & \\
\hline Saturius & 1 & & & & 1 & & & & \\
\hline Scribonius & 1 & & & & & & & & 1 \\
\hline Sediatio & 1 & & & & 1 & & & & \\
\hline Seius & 2 & & 1 & & 1 & & & & \\
\hline Scutia & 1 & & & 1 & & & & & \\
\hline Servilius & 1 & & & & & & & & 1 \\
\hline
\end{tabular}

\begin{tabular}{|c|c|c|c|c|c|c|c|c|c|}
\hline NOMEN & 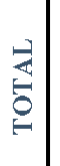 & 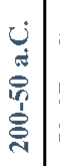 & 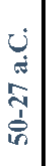 & 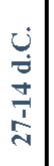 & 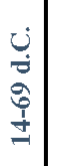 & 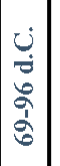 & 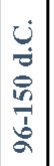 & 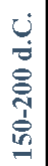 & 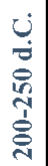 \\
\hline Sicinia & 2 & & & 2 & & & & & \\
\hline Silius & 1 & & & 1 & & & & & \\
\hline Statorius & 1 & & & 1 & & & & & \\
\hline Subrius & 2 & & & & & & 2 & & \\
\hline Sulpicius & 2 & & & 1 & & 1 & & & \\
\hline Talepius & 1 & 1 & & & & & & & \\
\hline Taurius & 1 & & 1 & & & & & & \\
\hline Terentius & 2 & & 2 & & & & & & \\
\hline Titius & 1 & & 1 & & & & & & \\
\hline Titinius & 3 & & 2 & 1 & & & & & \\
\hline Tongilius & 1 & 1 & & & & & & & \\
\hline Turpilius & 1 & & & 1 & & & & & \\
\hline Turullius & 1 & & & 1 & & & & & \\
\hline Valerius & 1 & & & & & & & 1 & \\
\hline $\begin{array}{l}\text { Vindicacia- } \\
\text { nus }\end{array}$ & 1 & & & & & & & & 1 \\
\hline Valeria & 2 & & & & 2 & & & & \\
\hline Verati & 1 & 1 & & & & & & & \\
\hline Vereius & 1 & & 1 & & & & & & \\
\hline Vergilius & 6 & & & 1 & 5 & & & & \\
\hline Vinuleius & 2 & & & 2 & & & & & \\
\hline Voconius & 1 & & & & 1 & & & & \\
\hline
\end{tabular}

Figura 9: Familias aparecidas en la epigrafía por periodo.

con cognomen de origen oriental, hecho posiblemente relacionado con el comercio de esclavos de Carthago Nova con el Mediterráneo oriental (Beltrán, 2004: 151-175), o incluso algunos casos donde el nomen del liberto está relacionado con las familias mineras locales (Domergue, 1990: 321), aunque esto resulta muy difícil de asegurar con certeza, puesto que no tenemos muchos datos arqueológicos sobre el sistema minero y la manumisión de esclavos de las minas o de otro tipo para la ciudad de Carthago Nova.

La presencia de mujeres en la epigrafía es otro factor a tener en cuenta para conocer el grado de participación local de un sector de la sociedad escasamente representado en las fuentes clásicas. En total, se han recogido 62 inscripciones (18,56\% del total), aunque en algunos casos aparecen varios nombres en una misma pieza. La distribución temporal muestra una sintonía general con los datos generales pero su presencia a nivel porcentual por etapa muestra un crecimiento de su presencia, que pasa del $4 \%$ del total en época tardorepublicana al $26 \%$ durante la etapa Julio-Claudia para finalmente volver a descender en la segunda mitad del siglo II d.C. (Fig. 11). Este fenómeno tiene relación con el alto número de inscripciones, especialmente las funerarias, encontradas durante la primera mitad del siglo I d.C. en la ciudad. La mayor parte de las inscripciones son de tipo funerario (58 de 62), mientras que hay 2 ejemplos de tipo monumental y 2 de tipo honorífico (Abascal y Ramallo, 1997: no 32 y 44), uno de ellos un pedestal de serpentina gris dedicado a Iulia Avita Mamea, madre del emperador Alejandro Severo. Al igual que con los libertos, resulta lógico ver que la mayor parte de los ejemplos se adscriban al mundo funerario, ya que es un tipo de inscripción más recurrente en todos los niveles sociales por su componente simbólico-religioso y por tratarse de un ritual trasversal a toda la sociedad, además de que la presencia de mujeres de clase alta en inscripciones públicas de tipo monumental u honorífico estuvo mucho más limitada en comparación a los hombres, ya que su participación en la vida pública fue fuertemente restringida o incluso prohibida, caso de los cargos políticos. Por esta razón, toda presencia de epígrafes donde se haga mención a mujeres adquiere mayor importancia para la investigación.

La aparición de cognomina púnicos nos permite conocer mejor la representación de ciertos sectores sociales en los epígrafes conservados hasta hoy. En el caso de Carthago Nova, estamos ante una ciudad de fundación púnica, localizada dentro de los circuitos comerciales del Mediterráneo, de modo que no resultaría ajeno encontrar pistas en la nomenclatura sobre 


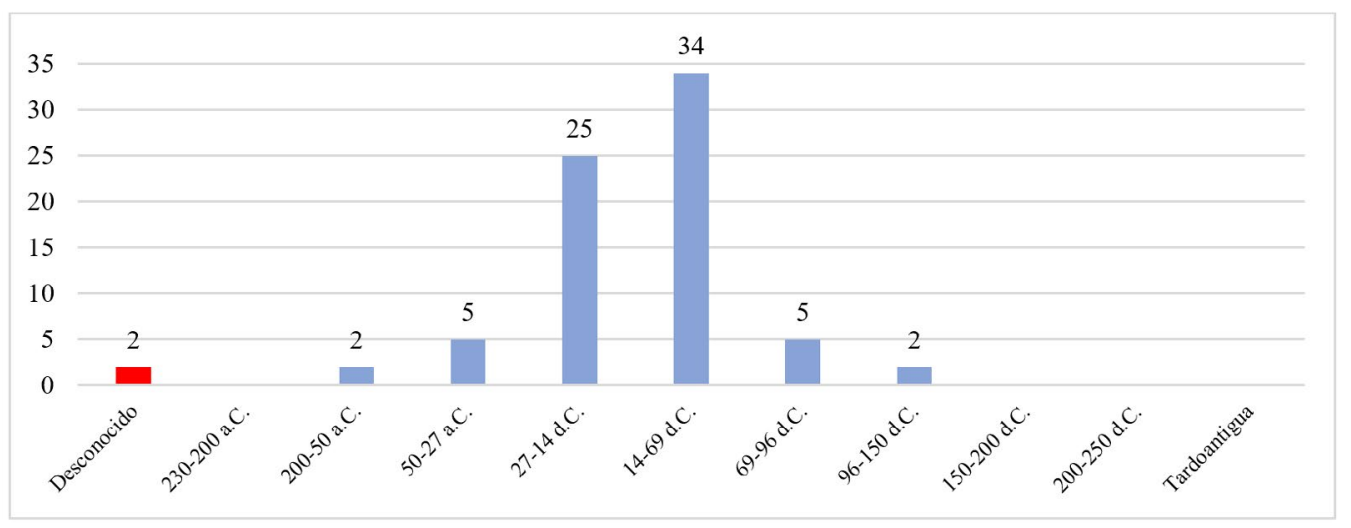

Figura 10: Presencia de libertos por periodo.

población descendiente de púnicos, bien comerciantes o bien habitantes sometidos al poder romano tras la conquista de la ciudad. Hemos seleccionado los epígrafes que se mencionan en un artículo del catedrático de la Universidad de Murcia Rafael González, el cual incluía una vasija donde se menciona a un individuo con tria nomina, siendo su cognomen «Sedbal» (González, Belmonte y Marín, 2014: 97-109). En total, se han recogido 14 epígrafes, de los cuales 10 son funerarios, y un caso para los de tipo evergético, honorífico, monumental y sobre instrumenta. En cuanto al material, 9 de los 14 han sido realizados sobre caliza gris local, 2 sobre mármol blanco, uno sobre plomo y uno como marca realizada sobre cerámica, quedando un caso sin conocerse su material. La distribución cronológica muestra una sintonía general con el registro de todas las demás piezas, aunque resulta destacable que no encontramos ni un solo ejemplo hasta la segunda mitad del siglo I a.C (Fig. 12).

Los epígrafes escritos en griego muestran una problemática similar a los de nombres púnico, ya que también son anecdóticos dentro del registro en comparación a los más de 300 que suman los escritos en latín. En total, se han recogido 9 ejemplos, de los cuales 8 aparecen con posterioridad al siglo II d.C. y llegando hasta la Tardoantigüedad. El único ejemplo anterior a este periodo es una placa con la inscripción $N K E\left(\mathrm{n}^{\circ}\right.$
268) realizada sobre hueso y fechada en el siglo III a.C. (García y Giménez, 2007: 105-122; Hoz, 2014: 292). Por tanto, tenemos una distribución temporal muy dispar, que no coincide porcentualmente con las cronologías tardorrepublicanas y altoimperiales de la mayoría de los epígrafes, pero sí con las tardías, llegando a ser casi la totalidad de ellas. En este sentido, pudo tener un papel decisivo la actividad de la ciudad durante la breve ocupación bizantina en los siglos VI y VII (Fig. 12).

Finalmente, se tuvo en cuenta si las piezas habían desaparecido o no como una columna más de la tabla, de manera que se pudiese ver hasta qué punto los materiales podían ser estudiados de nuevo o sólo contamos con la información recogida por los autores. En total, hay 66 inscripciones perdidas, es decir el 20\% de la colección. La mayor parte de las piezas desaparecidas está fechada en torno a la primera mitad del siglo I d.C., época de mayor esplendor monumental de la ciudad (Fig. 14). El tipo de texto que más aparece es el funerario, realizado sobre placa. Del material, tan sólo conocemos 47 de las 66 , de las cuales 10 son de caliza gris local y 5 de mármol blanco, coincidiendo con los materiales más usados en la ciudad para las construcciones arquitectónicas públicas de época altoimperial y tardoantigua (Vizcaíno, 2002: 207-220).

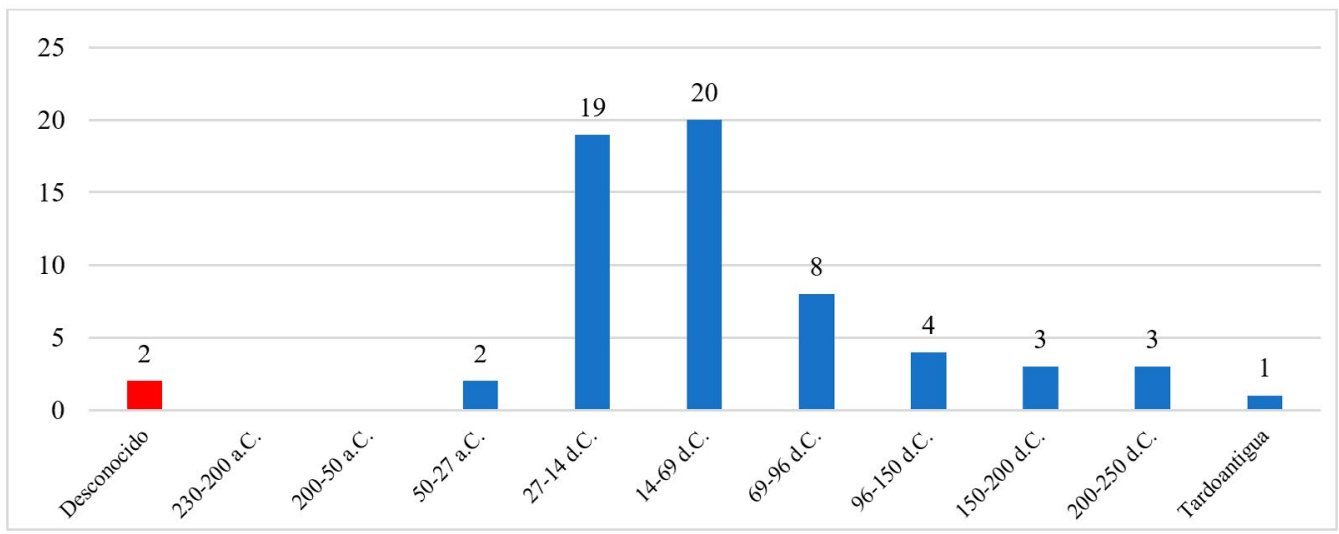

Figura 11: Epígrafes con mujeres por periodo. 


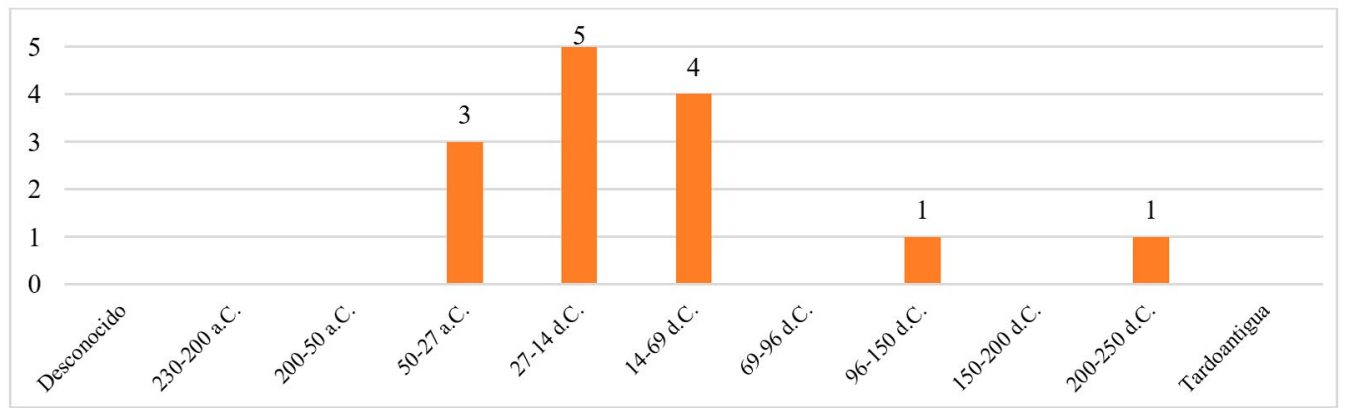

Figura 12: Epígrafes con cognomina púnicos.

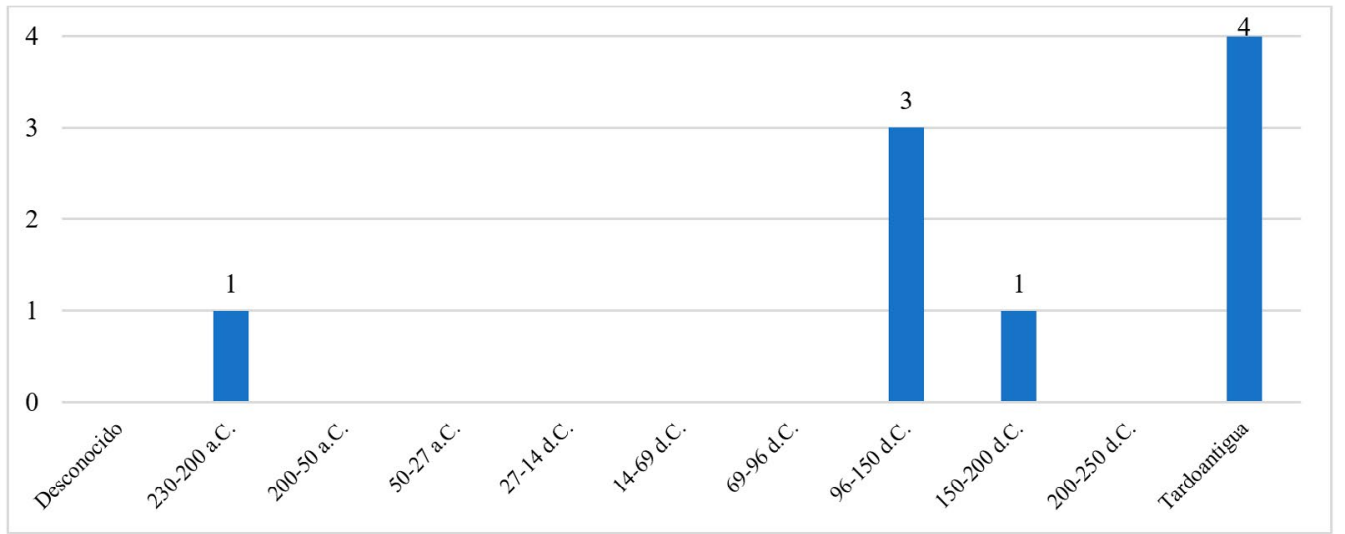

Figura 13: Epígrafes escritos en griego por periodo.

\section{ANALISIS ESPACIAL}

Para el análisis sobre la localización de los epígrafes se han traspasado a coordenadas UTM en sistema de referencia terrestre ETRS89 zona 30 norte (EPSG: 25830) todos aquellos datos publicados que pudieran dar mínimamente pistas sobre el lugar donde aparecieron las inscripciones (calles, solares, edificios, etc.). En total, se ha encontrado algún tipo de dato para 305 de 334 epígrafes, de modo que han quedado $29 \sin$ haber podido ser localizados de ningún modo. Se ha mantenido el nombre original de las localizaciones en la tabla, aunque se ha localizado en el mapa en su posición real, evitando confusiones por el cambio del viario urbano en los últimos dos siglos (Casal, 1986).
También, como hemos mencionado anteriormente, se ha mantenido la numeración original de los 229 epígrafes de la obra de Abascal y Ramallo (1997) y respetado dicho orden hasta la propia cifra dentro de la base de datos.

El primer dato estudiado en los mapas ha sido la contextualización de las piezas, intentando distinguir aquellas zonas donde se ha perdido más información de aquellas donde sí tenemos datos propios de una metodología moderna. Se ha tenido en cuenta como criterio si las piezas se encontraban contextualizadas al describirse por primera vez o habían sido estudiadas fuera de su contexto arqueológico, obteniendo un total de 174 piezas contextualizadas y 160 sin contexto. Esta cifra responde a que a lo largo de los siglos

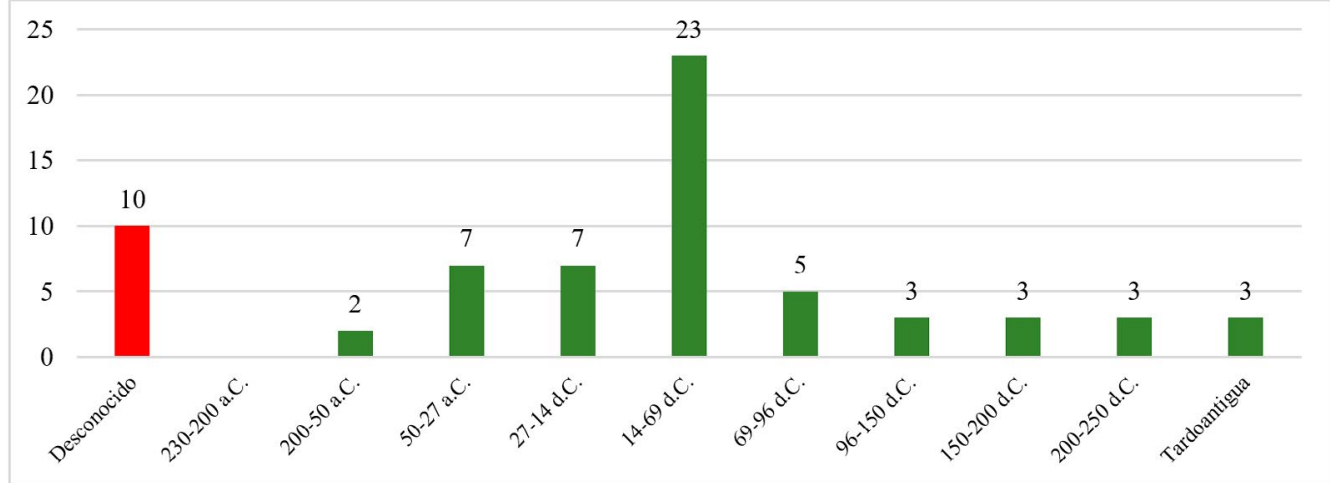

Figura 14: Inscripciones desaparecidas por periodo. 
se reutilizaron materiales romanos para usos funerarios o en edificaciones posteriores. En otros casos, las piezas fueron extraídas sin una metodología buena y nunca quedó constancia de su lugar de hallazgo original pero sí del lugar donde fueron albergadas con posterioridad. Debido a las necesidades de material de la ciudad, se recurrió durante siglos al expolio de piezas pétreas para otro tipo de construcciones como las defensivas o domésticas. Esto ha provocado que la zona del Castillo de la Concepción sea un área plagada de piezas descontextualizadas (Fig. 15). Asimismo, en el cerro de la Concepción estuvo situada la Casa de los Cuatro Santos, edificio que sirvió de almacén para las inscripciones que se encontraban y que finalmente fue derruido en el siglo XIX. Otro edificio que sufrió igual fortuna fue el antiguo ayuntamiento, situado en la misma parcela del actual, y que fue destruido junto con algunas inscripciones que se encontraban en su interior. A estos lugares se suman la zona de la calle Mayor y el arsenal, así como el propio foro romano, expoliado desde la Antigüedad. Gracias al artículo «El foro de Carthago Nova. Estado de la cuestión» del monográfico Fora Hispaniae (Noguera, Soler, Madrid y Vizcaíno, 2009: 217-302) hemos podido reconstruir parcialmente la dispersión de los materiales epigráficos del foro y cómo acabaron siendo reutilizados en otros puntos del entorno urbano (Fig. 16).
La localización de los epígrafes por cronología nos ofrece una visión distinta de la ciudad romana (Fig. 17). El centro urbano muestra una alta concentración de piezas sin cronología, con una gran presencia mayoritaria de los epígrafes del arco cronológico 50 a.C. - 50 d.C. Los mayores focos de concentración se encuentran en el cerro del Molinete y el teatro romano, los yacimientos más extensos y mejor estudiados de toda la ciudad hasta el día de hoy. A nivel global, si realizamos un desglose de la localización de las inscripciones y la aparición de algunas piezas destacables según periodos cronológicos el resultado es el siguiente:

230-200 a.C.: De la fundación de la ciudad y su breve fase púnica sólo conservamos un epígrafe, grabado en griego sobre hueso y encontrado en Monte Sacro $\left(n^{\circ} 276\right)$, el cual representa un caso único para toda la ciudad (García y Giménez, 2007: 105-122; Hoz, 2014: 292).

200-50 a.C.: Durante el periodo republicano destacan algunas piezas como los mosaicos a Atargatis (Abascal y Ramallo, 1997: $n^{\circ}$ 205) en el cerro del Molinete (Ramallo y Ruiz, 1994) y el sacellum dedicado a Jupiter Stator en el Cabezo Gallufo ( $\mathrm{n}^{\circ}$ 204), ambos fechados en torno a los siglos II-I a.C. En 2005 se encontró un lacus ( ${ }^{\circ}$ 290) erigido por Pompeyo Magno (Ramallo y Murcia, 2010) aunque

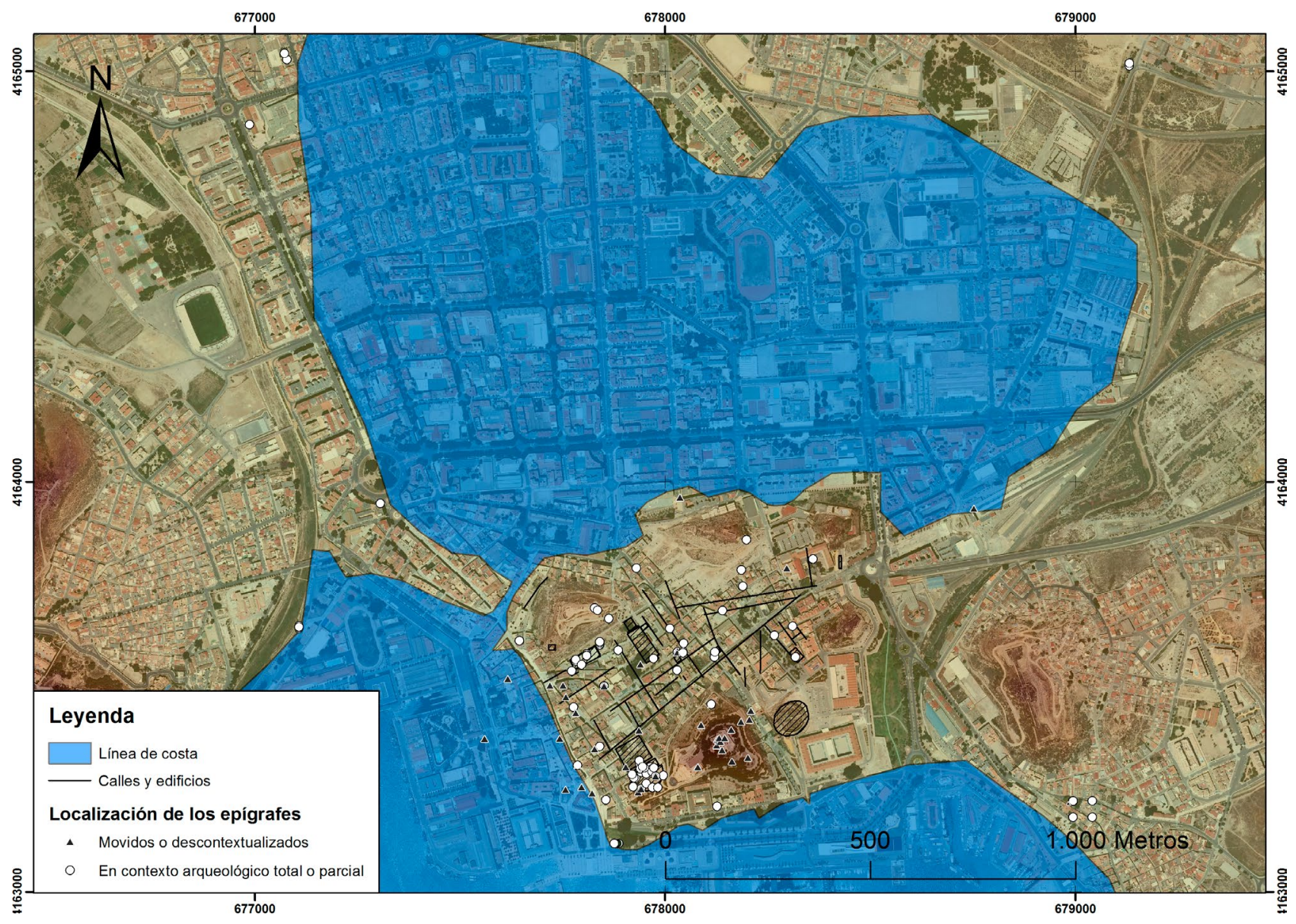

Figura 15: Localización de los epígrafes por su contexto arqueológico. 


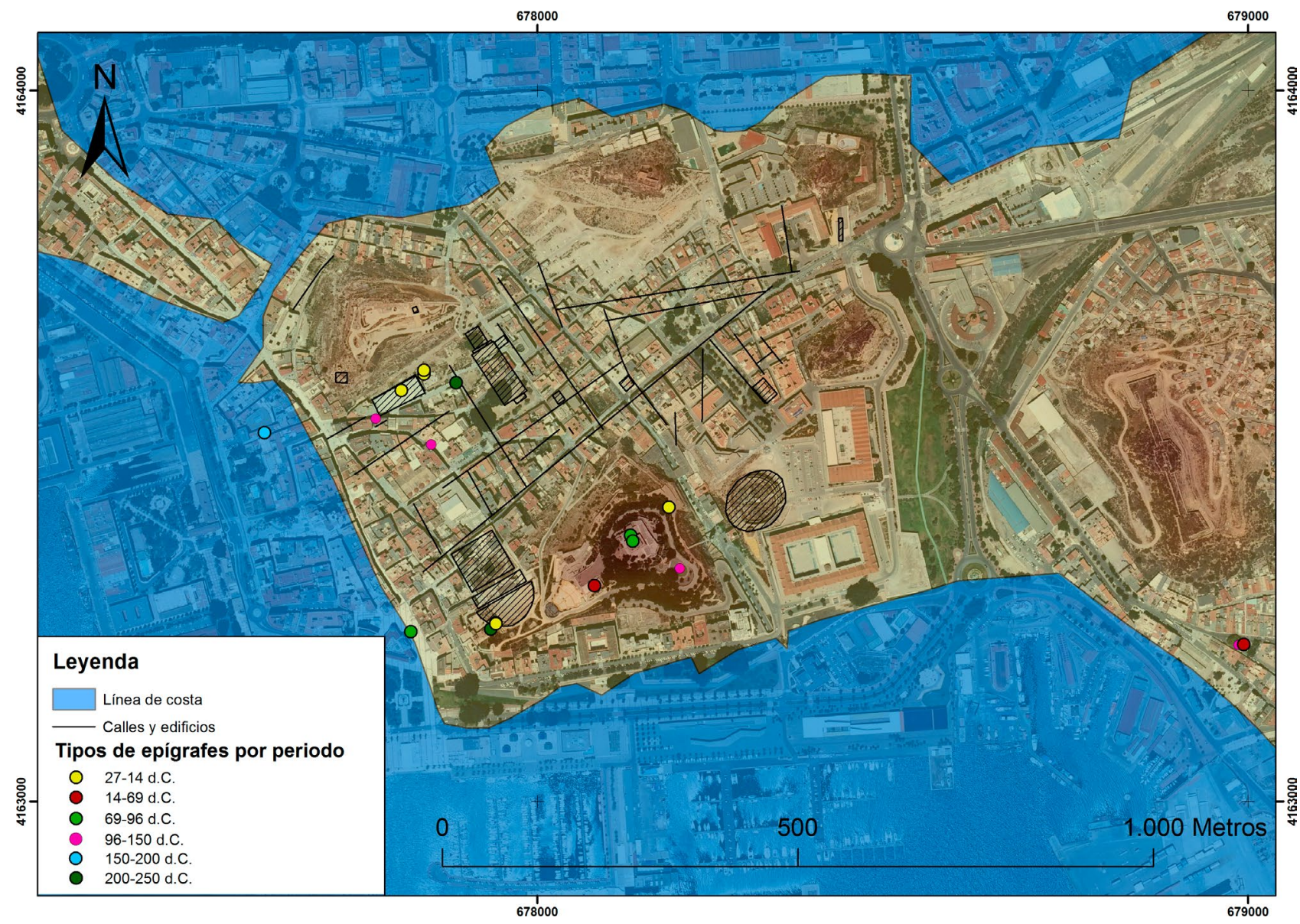

Figura 16: Localización de los epígrafes expoliados del foro de la ciudad.

volvemos a encontrar muy pocos epígrafes de este periodo (6).

50-27 a.C.: En este periodo se multiplica el número de epígrafes, aunque muchos de ellos han sido descontextualizados. Destacan dos fragmentos de litterae aureae del teatro romano (Abascal y Ramallo, 1997: $\mathrm{n}^{\circ} 16$ y 17) así como la aparición de inscripciones en el área oriental de la ciudad $\left(\mathrm{n}^{\circ} 199,261\right.$ y 191) y un mosaico de contexto doméstico con la inscripción salve $\left(\mathrm{n}^{\circ} 206\right)$. También son muy llamativas las inscripciones religiosas en honor a Hércules Gaditano $\left(\mathrm{n}^{\circ} 35\right)$ y un bloque de caliza gris dedicado a Isis y Serapis encontrado en el Molinete en 1975 ( $\mathrm{n}^{\mathrm{o}}$ 38). De esta cronología es el conjunto de lingotes de plomo encontrados en el área portuaria de la ciudad $\left(\mathrm{n}^{\circ} 232,233\right.$, 303, 307, 309-312, 316-317) y el pecio de Escombreras $\left(\mathrm{n}^{\circ} 240,305\right)$, restos que certifican la actividad del comercio marítimo y de las minas.

27-14 d.C.: En este periodo la ciudad experimenta un gran crecimiento. Destacan inscripciones como el mosaico de la casa de Salvius (n ${ }^{\circ} 262$ ), el cual nos da pistas sobre una posible área residencial y monumentalizada en la parte oriental de la ciudad (Madrid, Celdrán y Vidal, 2005). En el Molinete tenemos más inscripciones religiosas $\left(\mathrm{n}^{\circ} 318\right)$, mientras que en el foro aparecen piezas de gran calidad como los fragmentos sobre mármol blanco ( $\mathrm{n}^{\circ} 246$ y 248) encontrados en
1995 (Noguera y Abascal, 2003). En las Puertas de Murcia, en 1875, apareció una columna de travertino rojo dedicada por los piscatores et propolae en honor a los Lares Augustales y Mercurio, la cual ha sido fechada entre el 13 y 14 d.C. (Abascal y Ramallo, 1997: $\mathrm{n}^{\circ} 36$ ). Por último, los restos de epigrafía funeraria periurbanos definen las zonas de necrópolis de San Antón, Torre Ciega y Santa Lucía, situadas en los accesos terrestres a la ciudad.

14-69 d.C.: En este periodo tenemos una gran cantidad de piezas en el Molinete (Abascal, Noguera y Madrid, 2012: 287-296) y en las necrópolis de Santa Lucía y San Antón (Abascal y Ramallo, 1997: n 7681), aunque ahora aparece una zona de necrópolis en la parte occidental de la ciudad, junto a la Rambla de Benipila, denominada como necrópolis de la Concepción y de la cual conocemos muy poco a día de hoy (Abascal y Ramallo, 1997: ${ }^{\circ}$ 96-102).

69-96 d.C.: Durante estos años comienza a registrarse un descenso en la cantidad de materiales epigráficos (25 en total), la mayoría descontextualizados. Encontramos algunas piezas mejor estudiadas en el Molinete $\left(\mathrm{n}^{\mathrm{o}} 144\right.$ y 280$)$ y el teatro $\left(\mathrm{n}^{\circ} 149\right)$, así como una inscripción religiosa en el área de Santa Lucía (Abascal y Ramallo, 1997: $\mathrm{n}^{\circ}$ 40).

96-150 d.C.: Con la crisis minera y el descenso del comercio, se observa en la ciudad un periodo 


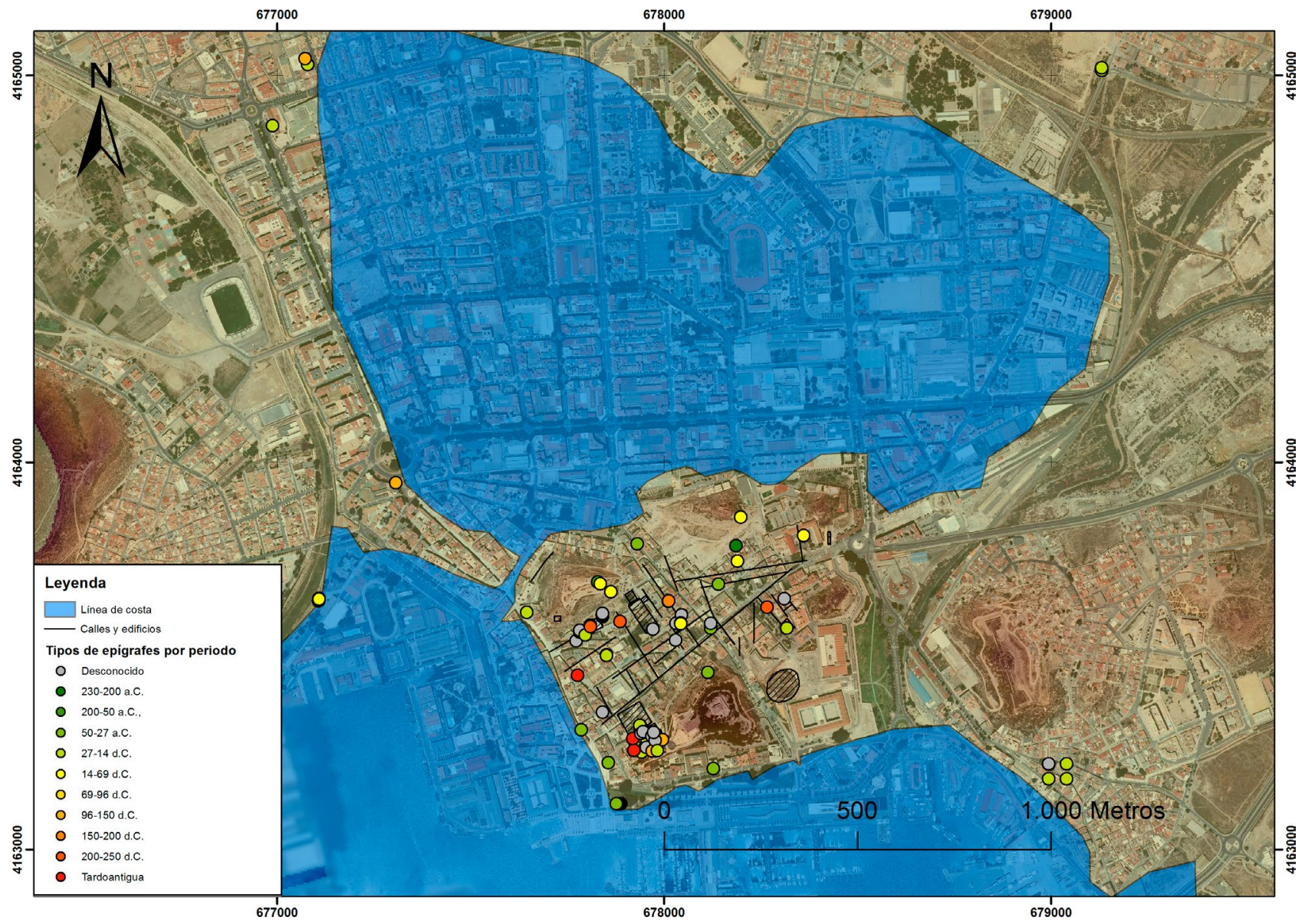

Figura 17: Localización de los epígrafes (contextualizados arqueológicamente) por periodo.

de decadencia que afectó a la epigrafía. Durante este periodo las piezas se localizan en la parte occidental, confirmando los síntomas de una regresión urbana (Quevedo, 2013). Cabe mencionar algunos grafitos ( $\mathrm{n}^{\mathrm{o}}$ 294-296) y una inscripción en griego en el Molinete ( $n^{\circ}$ 293) (Hoz, 2014: 302). También es digno de mención el epígrafe funerario de un beneficiarius consularis encontrado en el año 2000 en la Plaza de España $\left(\mathrm{n}^{\mathrm{o}} 241\right)$.

150-200 d.C.: Con apenas una decena de inscripciones, la mitad sin contexto, este periodo nos ofrece poca información a través de su epigrafía. Tenemos de nuevo algunas piezas que aparecen en el Molinete (Abascal y Ramallo, 1997: $\mathrm{n}^{\circ} 115$ y 128), la Plaza de España (n $\left.{ }^{\circ} 169\right)$, la Calle Jara $\left(n^{\circ} 186\right)$ y la Calle Arco de la Caridad ( $\left.n^{\circ} 331\right)$. En total, 8 de las 10 piezas conservadas son funerarias, por lo que apenas nos ofrecen información de la actividad política de la ciudad. Resulta curioso el caso del epígrafe dedicado a Aemilia Mellusa ( $\left.\mathrm{n}^{\circ} 116\right)$ ya que fue descubierto por Montanaro en el siglo XVII y posteriormente perdido hasta ser reencontrado a finales del siglo XX (Abascal, 2013: 30).

200-250 d.C.: De este periodo es de resaltar el pedestal honorífico de serpentina gris azulada dedicado a Iulia Mamea (Abascal y Ramallo, 1997: no 44), último acto de este tipo en la ciudad. Recientemente ha aparecido en zona sur del Molinete un grafito pintado sobre pared dedicado a Heliogábalo (n 329) así como una inscripción monumental de un curator rei publicae $\left(\mathrm{n}^{\circ} 333\right)$ aparecida en las termas del foro (Fernández, Ramallo y Suarez, 2016).

Tardoantigüedad: Todos los materiales de esta época aparecieron en el área occidental de la ciudad, espacio que coincide con la posterior Cartagena medieval. De las 9 inscripciones de esta época conservamos 4 escritas en griego. Destaca la lápida de Comenciolo (Abascal y Ramallo, 1997: no 208) aparecida en la plaza del antiguo ayuntamiento.

La distribución espacial por criterio del tipo de texto nos sirve para diferenciar las distintas zonas en las que se dividió la ciudad (Fig. 18), así como sus fases (Noguera y Madrid, 2014: 24). Comenzamos por las inscripciones funerarias, las cuales nos delimitan 4 necrópolis alrededor de la ciudad (Ramallo, Murcia y Vizcaíno, 2010: 222) situadas en el barrio de la Concepción, San Antón, Torre Ciega y Santa Lucía. Estas zonas coinciden con los límites espaciales del antiguo estero (García, García, Torres y Corbalán, 2013: 5) y con las vías naturales de acceso a la ciudad (Ramallo, 2011: 90). De todas estas necrópolis, la de la Concepción es la que menos conocemos, ya que apenas se ha revisado el material o prospectado la 


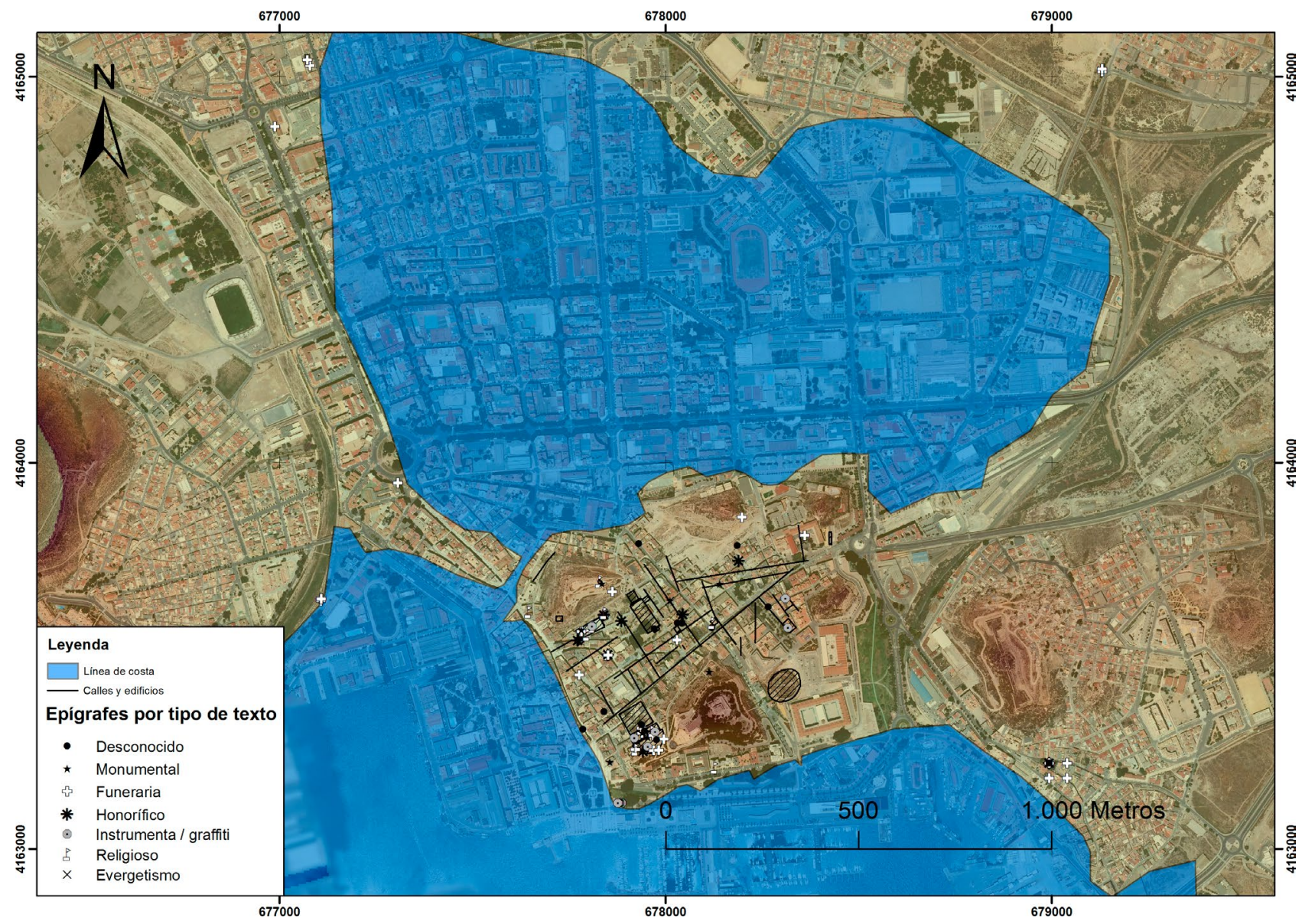

Figura 18: Localización de los epígrafes (contextualizados arqueológicamente) por tipo de texto.

zona posteriormente. El patrón de aparición de epígrafes funerarios en estas necrópolis marcaría las pistas para trazar la posible localización de las vías romanas, aunque todavía queda por concretar la localización de la puerta oriental de la ciudad, así como la posible vía de acceso occidental, en el punto de comunicación entre el estero y el Mar de Mandarache.

Respecto a las inscripciones monumentales, conservamos un gran número de ellas en el teatro y el foro gracias a los estudios arqueológicos que allí se han realizado, mientras que hay un gran porcentaje que está descontextualizado, especialmente las reutilizaciones para el castillo de la Concepción, aprovechando los materiales de las murallas, el teatro y el foro. Las inscripciones sobre instrumenta coinciden con joyas encontradas en el teatro ( $n^{\circ} 265$ y 330), anclas y lingotes encontrados en el puerto y grafitis localizados en el «edificio del atrio» del cerro del Molinete $\left(\mathrm{n}^{\circ} 284\right.$, 286,287 y 329). Las inscripciones honoríficas son menos comunes, localizadas en el área del foro, aunque dispersas por toda la ciudad (Noguera, Soler, Madrid y Vizcaíno, 2009). Otro lugar donde aparecen es el teatro (Ramallo, 1996: 307), aunque en menor número.

Las piezas religiosas tienen un patrón de localización muy concreto, con dedicaciones a Serapis, Isis y Atargatis en la zona sur del Molinete ( $n^{\circ}$ 37, 38, 205, 283,284 y 318 ), lo que podría relacionar toda la zona con un recinto de culto. Se ha propuesto que las dedicaciones a estas divinidades salutíferas sean debido a los problemas de salud surgidos por la existencia del estero al norte de la ciudad (Uroz, 2003; Abascal, 2011; Egea, 2012). Aparecen también dedicaciones a Fortuna ( $\left.\mathrm{n}^{\circ} 12, \mathrm{n}^{\circ} 325\right)$, al emperador ( $\left.\mathrm{n}^{\circ} 13\right)$, al genio Castelli $\left(\mathrm{n}^{\mathrm{o}} 33\right)$, el Hércules gaditano $\left(\mathrm{n}^{\mathrm{o}} 35\right)$, Mercurio ( $\left.\mathrm{n}^{\mathrm{o}} 36\right)$, la Victoria Augusta $\left(\mathrm{n}^{\mathrm{o}} 39\right)$ y finalmente algunas ya de época cristiana ( $n^{\circ} 209$ y 212). Respecto a las inscripciones evergéticas, apenas tenemos ejemplos en la parte occidental de la ciudad $\left(n^{\circ} 24,28,34\right.$ y 332). Por su parte, los mosaicos que se conservan en el recinto urbano son de dos tipos: domésticos o privados ( $\mathrm{n}^{\mathrm{o}} 206,262$ y 325), localizados en el sector oriental de la ciudad, posiblemente un barrio residencial (Fernández y Quevedo, 2007-2008: 273), o bien religiosos, consagrados a las divinidades de Júpiter Stator $\left(\mathrm{n}^{\circ}\right.$ 204) y Atargatis ( $\left.n^{\circ} 205\right)$.

La dispersión espacial por tipo de material también es otro factor para que distingamos las zonas más ricamente monumentalizadas (Fig. 19). Es el caso de las piezas realizadas en mármol blanco, mármol crema y travertino rojo, aparecen en el teatro y foro, usadas para el programa decorativo (Soler, 2005b: 148). Las piezas de serpentina gris azulada y mármol gris de Hipona, sólo se encuentran en el área del foro y el augusteum y el teatro (Soler, 2005a: 38). Este proceso de 


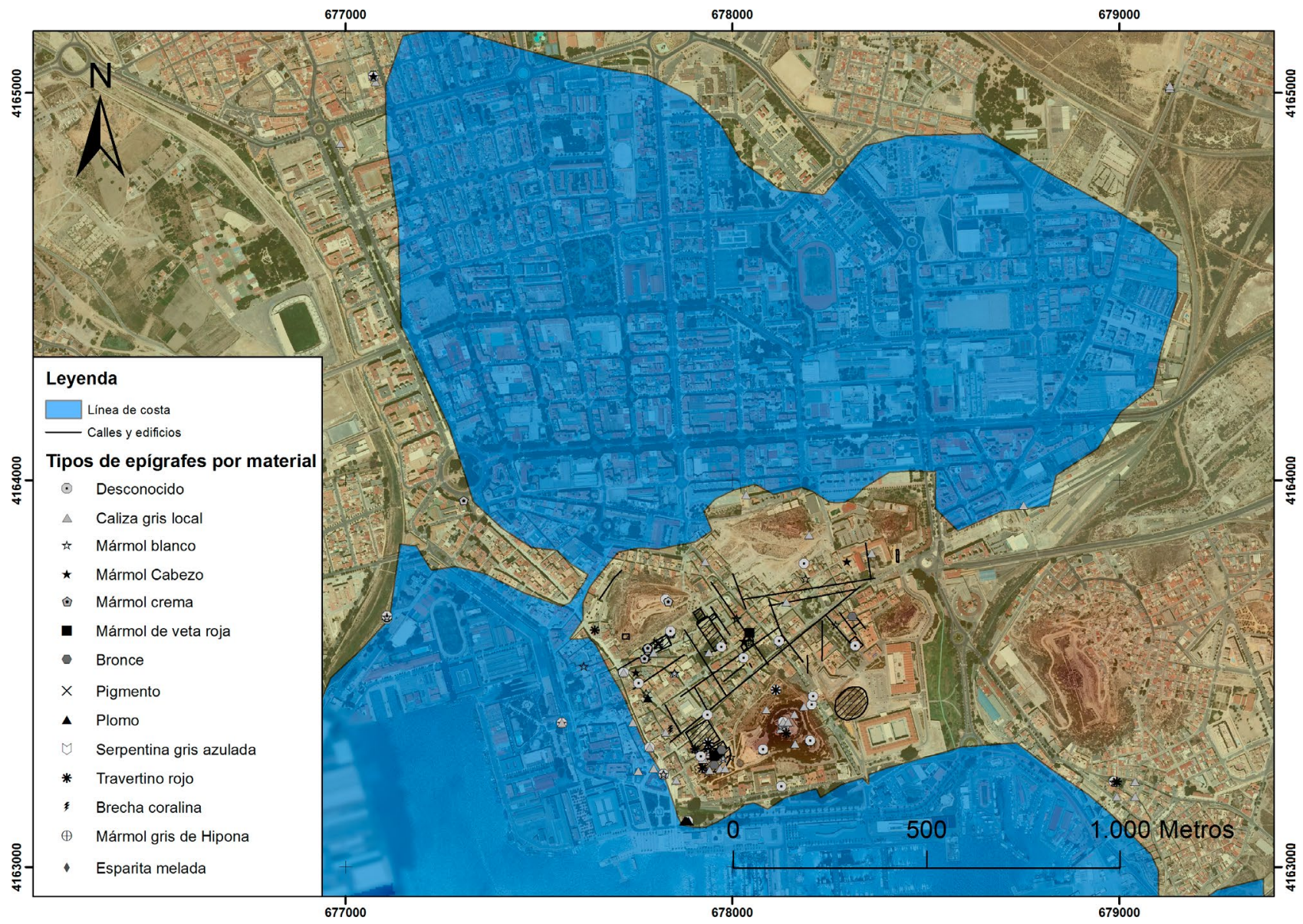

Figura 19: Localización de los epígrafes por material utilizado.

marmorización y enriquecimiento monumental de la ciudad ocurrió en un periodo de un siglo, coincidiendo con el máximo registro de epígrafes locales dentro de la base de datos.

Finalmente, el mapa resultante de representar los tipos de interpunción (Fig. 20) nos ofrece información sobre algunas piezas descontextualizadas, caso de las inscripciones del castillo, donde abundan las piezas monumentales de interpunción cuadrada del siglo I a.C. La de tipo triangular aparece de manera regular por toda la ciudad, especialmente la parte occidental del tómbolo. Como elemento a destacar, la interpunción de flecha aparece en las necrópolis de Santa Lucía y la Concepción mientras que la interpunción con hedera sólo aparece en el teatro y la necrópolis de San Antón.

\section{CONCLUSIONES}

Las inscripciones de Cartagena ilustran cómo dentro del espacio urbano el paso del tiempo ha alterado el contexto arqueológico, especialmente en aquellas zonas localizadas dentro del casco histórico. Este fenómeno es muy común en ciudades como Cartagena, cuyo crecimiento durante la creación del arsenal y con la Revolución Industrial supuso una gran modificación de su aspecto como ciudad portuaria, lo que terminó por afectar al estado de los epígrafes y su posterior conservación. No ha sido hasta las últimas décadas del siglo XX cuando los cambios urbanísticos han ido acompañados de una planificación y un trasfondo legal moderno donde se considerase el patrimonio arqueológico como un elemento más a tener en cuenta en los proyectos que afectasen a los niveles de suelo bajo el centro de la ciudad. En este sentido, el repaso a la historiografía de la epigrafía local nos permite ver con perspectiva cómo ha sido el estudio local en los últimos siglos y la gran cantidad de avances que se han conseguido.

Los datos técnicos de las inscripciones nos dibujan un modelo aproximado de la epigrafía del área urbana y periurbana en la antigua Carthago Nova. A nivel cronológico, podemos observar cómo el registro de todos los epígrafes se concentra enormemente en un periodo de siglo y medio, desde mitad del siglo I a.C., tras su promoción a colonia, hasta la segunda mitad del siglo I d.C. Este periodo coincide con la cronología de las principales obras públicas de la ciudad (Rama1lo, 2004; Ramallo, 2011) y la mejora del urbanismo de la misma desde finales del siglo I a.C. (Meroño, 2014). Destaca la gran cantidad de inscripciones fechadas en época tardorrepublicana, las cuales suponen actualmente la mayor colección de toda la Península 


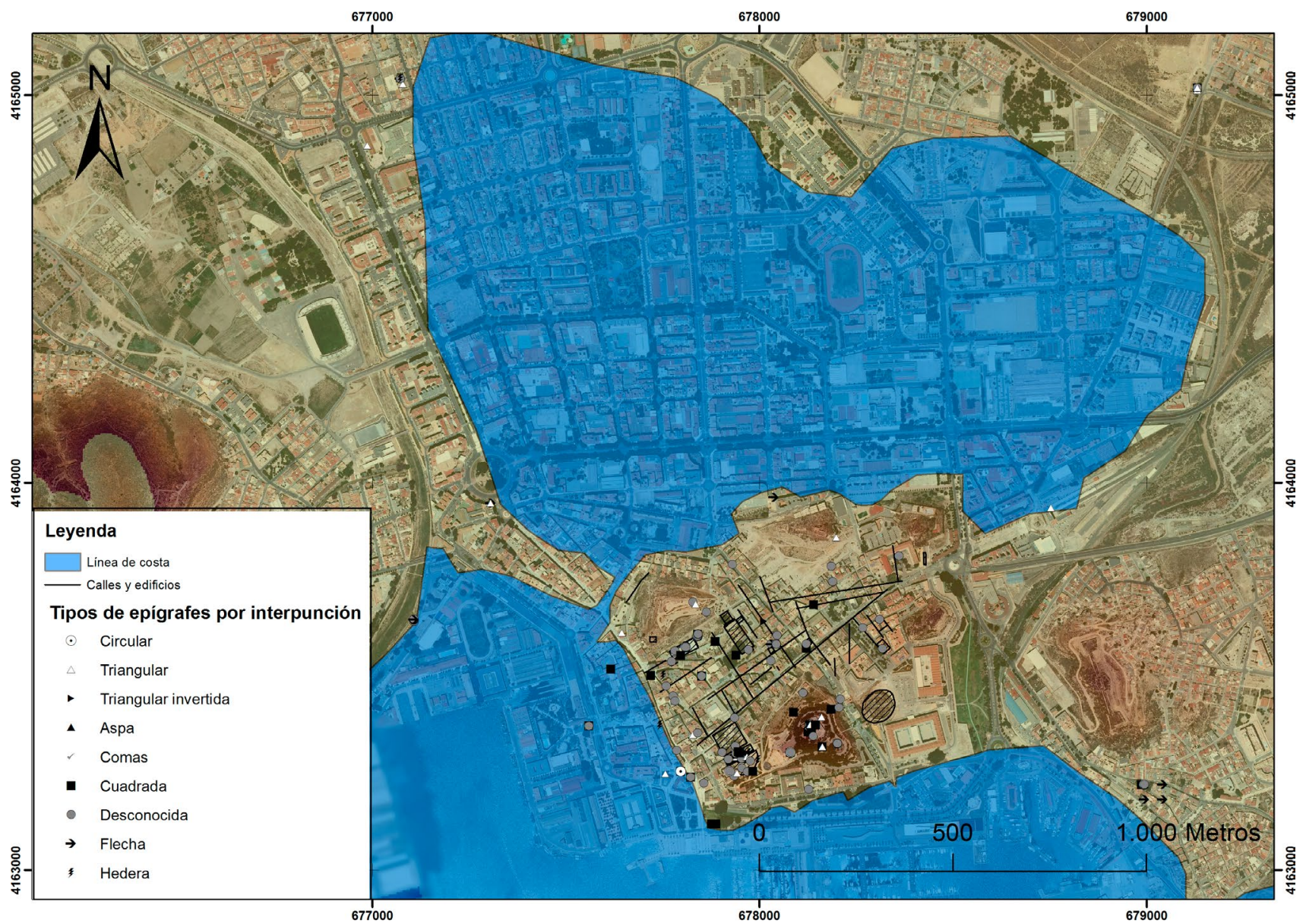

Figura 20: Localización de los epígrafes por tipo de interpunción.

Ibérica para este periodo (Abascal, Ramallo y Schmidt: 2017, 72). Asimismo, el alto número de epígrafes en este arco cronológico indicaría un periodo de crecimiento a nivel demográfico y económico durante estos años, al amparo de la riqueza de la sierra minera de Cartagena-La Unión y el comercio marítimo del puerto (Berrocal, 2008).

La cuestión de la riqueza minera es un tema muy relacionado con la propia extracción de materia prima para los epígrafes, además de ser un rasgo de la ciudad muy citado en las fuentes. Estrabón (III, 4, 6) afirma que «es la ciudad más importante de esta costa por su fuerte posición, sus murallas, sus puertos, su laguna, sus minas de plata y su salazón». Autores clásicos de distintas épocas inciden mucho en la importancia de la minería de plata (Estrabón, III, 2, 10; Diodoro, 5, 38; Plinio, XXXIII, 31, 96), llegando a citarse en el siglo II a.C. la producción de 10.000 dracmas de plata al día (Polibio, XXXIV, 9, 8). El fin de este sistema de explotación pudo ser la principal causa del declive de la ciudad y también de la paulatina desaparición de epígrafes en el área urbana, por lo que futuros estudios sobre la minería y las explotaciones de piedra ayudarán a conocer mejor el sistema económico sobre el que se sostenía el proceso de extracción, labrado, venta, importación e incluso exportación de epígrafes a nivel local.
El gran crecimiento económico, patente en la edilicia monumental y los materiales fechados durante el cambio de milenio, se vio frenado a mitad del siglo I d.C., posiblemente por el agotamiento de las vetas de galena argentífera o del propio sistema comercial en general, el cual comenzó a diversificarse para contrarrestar los problemas económicos (Murcia, López y Ramallo, 2013:132). En el aspecto marítimo, los circuitos comerciales fueron cambiando durante el desarrollo del Alto Imperio. La ciudad dejó de ser un puerto importante para la redistribución a escala media y pequeña, por lo que se dio paso a un nuevo comercio a gran escala donde Carthago Nova era un puerto secundario y sus negocios de importación y exportación quedaban en segundo plano (Cerezo, 2015: 28). A nivel estratigráfico podemos corroborar esta decadencia si estudiamos las obras públicas. Desde las últimas décadas del siglo I d.C., la ciudad pasa de ser una capital que imita a la urbe a un pequeño núcleo de población deteriorado y abandonado tanto en el aspecto urbano como el institucional (Mata, 2014: 241-242). Se observa una regresión del área urbana hacia la parte occidental del tómbolo a partir del siglo II d.C. en adelante, dando lugar al germen de la posterior ciudad medieval (Martínez, 2004; Quevedo y Ramallo, 2015: 161-177).

Por otro lado, la gran mayoría de piezas funerarias están realizadas sobre caliza gris local o micrítica, un 
material que parece ser usado para diversas finalidades y por distintos estratos sociales desde finales del siglo I a.C. hasta la mitad del I d.C. A grandes rasgos, podemos dibujar dos modelos diferentes de los epígrafes en el registro: durante la época tardorrepublicana encontramos más piezas monumentales realizadas sobre caliza gris local y con interpunción cuadrada, así como más lingotes de plomo sellado, mientras que a partir de época augustea hay un gran protagonismo de la epigrafía funeraria sobre caliza gris, así como otros materiales marmóreos de gran calidad. Este cambio en las tendencias pudo deberse a varios aspectos, entre los cuales estaría la importación de modas de la propia Roma en época de Augusto, ya que el crecimiento de la ciudad durante su gobierno coincide con la mayor profusión de epigrafía en las provincias y Roma, todo ello parte de la renovación de la simbología del poder imperial (Alföldy, 1991: 573). De acuerdo con los datos cronológicos y técnicos de las piezas, se adoptó la interpunción triangular a partir de época de Augusto y la hedera y el círculo desde época Flavia, hecho que confirma la adopción de ciertas modas por parte de los talleres o bien la posible demanda de los clientes. Este fenómeno cultural no deja de ser un resultado del alto grado de romanización de la ciudad, al compartir una misma identidad y códigos culturales con la capital.

Respecto al material usado, se ha observado en la bibliografía más antigua cómo las descripciones que se ofrecen del tipo de piedra utilizada han quedado relevadas por análisis más modernos, en los cuales se ha tenido en cuenta la toma de muestras para laboratorio y la descripción científica del material. De cara al futuro, será conveniente realizar una revisión de aquellas piezas arqueológicas descubiertas a comienzos de siglo XX y conservadas, puesto que muchas de las descripciones antiguas pueden quedar refutadas, al tratarse de denominaciones muy ambiguas («piedra», «caliza» o «mármol») o incluso inexistentes.

Otro dato destacable en el cómputo es la información social que aparece en los textos de los epígrafes. Los porcentajes de libertos $(22,5 \%)$ y de mujeres $(18,6 \%)$ suman una cantidad destacable, especialmente durante la primera mitad del siglo I d.C., y en algunos puntos como la necrópolis de Santa Lucía. La presencia de este tipo de inscripciones no deja de ser un ejemplo de la vitalidad de la ciudad durante la época de mayor monumentalización del centro urbano. Sin embargo, hemos encontrado un alto número de piezas de las que no conocemos su cronología y material. Como hemos mencionado al principio, resulta normal la pérdida de información arqueológica en una ciudad tan cambiante a través de los siglos como Cartagena. Como parte de este hecho, se han perdido un $20 \%$ de los epígrafes, en su mayoría descubrimientos de la Edad Moderna que no han llegado a nosotros más que por autores de la época.

A nivel espacial, se observa en los mapas una cierta distorsión en la información provocada por el desigual conocimiento de la ciudad. Debido a que conocemos mucho mejor los restos del cerro del Molinete y el teatro romano que el resto de la ciudad, encontramos un gran foco de localización de epígrafes dentro de su área. También hay una distorsión creada por el gran número de epígrafes descontextualizados, prácticamente la mitad del total, aunque están localizados en unas áreas muy concretas (arsenal, ayuntamiento y castillo). Esto reduce mucho la cantidad de información espacial de las piezas conservadas, aunque nos muestra la verdadera potencia arqueológica del casco histórico. Por el contrario, contamos con poca información del área oriental de la ciudad, especialmente las zonas de los cerros de Monte Sacro, San José y Despeñaperros. Conforme avancen las excavaciones y se estudie mejor el perímetro urbano, podremos saber más sobre la existencia de epígrafes en el área oriental, especialmente los domésticos, los monumentales de los muros y posiblemente los funerarios en el área de acceso a la ciudad. Respecto a los límites espaciales del antiguo tómbolo, las investigaciones que se están llevando a cabo en materia de paleotopografía (proyecto Arqueotopos) y estudios de fondos portuarios nos dan información científica sobre los antiguos límites de la costa y los posibles problemas con el nivel freático y las aguas del estero en la Antigüedad.

Tras representar espacialmente los tipos de epígrafes sobre un mapa se han delimitado perfectamente cuatro zonas de necrópolis, las cuales coinciden con los límites naturales del antiguo estero y las principales vías de acceso a la ciudad en época antigua. Encontramos gran cantidad de inscripciones monumentales y honoríficas en el teatro y el foro, hecho que resulta lógico dadas las cualidades de estos espacios públicos. También se ha observado una alta concentración de piezas religiosas en el área meridional del cerro del Molinete, relacionadas con el culto a las divinidades orientales de Atargatis, Isis y Serapis. Las excavaciones dirigidas por José Miguel Noguera y María José Madrid en la llamada insula 2 del Molinete confirmarán estas sospechas, ya que algunos autores relacionan estos cultos con los problemas de abastecimiento y salubridad del agua (cf. Egea, 2012; Bernabé y Gómez, 2015). De cara al futuro, queda por estudiar de manera intensiva el edificio del anfiteatro y su programa epigráfico, tarea que se está llevando a cabo desde finales de 2016.

Como breve conclusión, los resultados de esta actualización metodológica han pretendido servir de espacio de trabajo abierto a la progresiva puesta al día de los datos, de manera que la digitalización de la información contenida en las publicaciones científicas sirva de primer paso hacia una mejor sistematización digital de la epigrafía de la ciudad en formatos de trabajo aptos para la estadística o para la utilización de capas de información sobre software de arqueología, especialmente el vectorial o los propios Sistemas de Información Geográfica. 


\section{REFERENCIAS}

AA.VV. (2004). Scombraria, la historia oculta bajo el mar. Catálogo de la exposición. Murcia: CARM.

Abascal Palazón, J. M. (2004). Cultos orientales en Carthago Nova. En AA. VV. Scombraria, la historia oculta bajo el mar. Catálogo de la exposición (pp. 102-106). Murcia: CARM.

Abascal Palazón, J. M. (2011). El cerro del Molinete y los cultos orientales en Carthago Nova. En J. M. Noguera y M. J. Madrid (Coords.). Arx Hasdrubalis. La ciudad reencontrada. Arqueología en el cerro del Molinete (pp. 118-119). Cartagena: CARM.

Abascal Palazón, J. M. (2013). Cuestiones epigráficas del conventus Carthaginiensis (Hispania Citerior), con algunas contribuciones póstumas de Géza Alföldy. En J. López Vilar (Ed.). Actes 1er. Congrés Internacional D'arqueologia y Món Antic (pp. 13-35). Tarragona: Fundació Privada Mútua Catalana.

Abascal Palazón, J. M. y Ramallo Asensio, S. (1997). La ciudad romana de Carthago Nova: la documentación epigráfica. Murcia: Universidad de Murcia.

Abascal Palazón, J. M., Die Maculet, R. y Cebrián Fernández, R. (2009). Antonio Valcárcel Pío de Saboya, Conde de Lumiares (1748 - 1808): apuntes biográficos y escritos inéditos. Madrid: Real Academia de la Historia.

Abascal Palazón, J. M., Noguera Celdrán, J. M. y Madrid Balanza, M. J. (2012). Nuevas inscripciones romanas de Cartago Nova (Cartagena, Hispania Citerior). ZPE, 182, 287-296.

Abascal Palazón, J. M., Noguera Celdrán, J. M. y Navarro Suarez, F. J. (Eds.) (2002). Cartagena romana: historia y epigrafía. Edición facsímil y estudio de Inscripciones de Carthago Nova, Hoy Cartagena, en el reyno de Murcia, ilustradas por el excelentísimo señor Conde Lumiares, individuo de la Academia de Ciencias y Artes de Padua. Murcia: Tabularium.

Abascal Palazón, J. M., Ramallo Asensio, S. y Schmidt, M. G. (2017). Carmen epigráfico funerario de Carthago Nova. ZPE, 201, 72-76.

Alföldy, G. (1991). Augusto e le iscrizioni: tradizione ed innovazione. La nascita dell'epigrafia imperiale. Scienze dell'Antichità. Storia, Archeologia, Antropologia, 5, 573-600.

Antolinos Marín, J. A. (2005). Prospección minero-metalúrgica antigua en la Sierra de Cartagena y su territorio adyacente. Memorias de arqueología de Murcia, 13, 581-602.

Antolinos Marín, J. A. (2008). La explotación de los recursos minerales en el entorno de Carthago Nova. En J. Uroz Sáez, J. M. Noguera Celdrán y F. Coarelli (Coords.). Iberia e Italia: Modelos romanos de integración territorial (pp. 619-632). Murcia: Tabularium.

Antolinos Marín, J. A. y Soler Huertas, B. (2007). Los orígenes de la arqueominería en la Región de Murcia (I): los hallazgos en la Sierra Minera de Cartagena-La Unión. Mastia, 6, 125-144.
Antolinos Marín, J. A., Fabre, J. y Rico, C. (2010). Las minas romanas de Carthago Nova. Avance de las investigaciones en la rambla del Abenque (Sierra de Cartagena). Mastia, 9, 151-177.

Antolinos Marín, J. A., Noguera Celdrán, J. M. y Soler Huertas, B. (2010). Poblamiento y explotación minerometalúrgica en el distrito minero de Carthago Nova. En J. M. Noguera Celdrán (Ed.). Poblamiento rural romano en el Sureste de Hispania. 15 años después (pp. 167-231). Murcia.

Barreda Pascual, A. (1998). Gentes itálicas en Hispania Citerior (218-14 d.C.). Los casos de Tarraco, Carthago Nova y Valentia. (Tesis Doctoral). Universitat de Barcelona. Barcelona.

Beltrán Lloris, F. (2004). Libertos y cultura epigráfica en la Hispania republicana. En F. Marco Simón, F. Pina Polo y J. Remesal Rodríguez (Eds.). Vivir en tierra extraña: emigración e integración cultural en el mundo antiguo (pp. 151176). Barcelona: Universitat de Barcelona.

Bernabé Crespo, M. B. y Gómez Espín, J. M. (2015). El abastecimiento de agua a Cartagena. Cuadernos Geográficos, 54(2), 270-297.

Berrocal Caparrós, M. C. (2008). Poblamiento y explotación intensiva durante época republicana en la sierra minera de Cartagena-La Unión. Un modelo de ocupación inicial. En J. Uroz Sáez, J. M. Noguera Celdrán y F. Coarelli (Coords.). Iberia e Italia. Modelos romanos de integración territorial (pp. 603-618). Murcia: Tabularium.

Casal Martínez, F. (1986). Historia de las calles de Cartagena. Murcia: Academia Alfonso X el Sabio.

Cerezo Andreo, F. (2015). El puerto de Carthago Nova. Tráfico marítimo a través de los contextos materiales de época augustea. En J. López Vilar (Ed.). Actes $2^{\circ}$ Congrés Internacional d'arqueologia y Món Antic (Vol. 2) (pp. 23-33). Tarragona: Fundació Privada Mútua Catalana.

Díaz Ariño, B. (2008). Epigrafía latina republicana de Hispania. Barcelona: Universitat de Barcelona.

Díaz Ariño, B. (2009). La Hispania Citerior, desarrollo económico e integración en época republicana: una aproximación epigráfica. $D H A, 35,1,115-152$.

Díaz Ariño, B. y Antolinos Marín, J. A. (2013). Los argentarii y las societates mineras de la zona de Carthago Nova. En J. López Vilar (Ed.). Actes 1er. Congrés Internacional D’arqueologia y Món Antic (pp. 115-120). Tarragona: Fundació Privada Mútua Catalana.

Domergue, C. (1990). Les mines de la Péninsule Ibérique dans l'antiquité romaine. Roma: École Française de Rome.

Egea Vivancos, A. (2012). Agua sagrada y agua ritual en los cultos urbanos y suburbanos de Carthago Nova. Gerion, 30, 219-242. DOI: http://dx.doi.org/10.5209/rev_GERI.2012. v30.41813

Estrabón (1998). Geografia. Libros III-IV. Madrid: Gredos.

Fernández Díaz, A. y Quedevo Sánchez, A. (2007-2008). La configuración de la arquitectura doméstica en Carthago 
Nova desde época tardorrepublicana hasta los inicios del Bajo Imperio. AnMurcia, 23-24, 273-309.

Fernández Díaz, A., Ramallo Asensio, S. y Suárez Escribano, L. (2016). Dos nuevos epígrafes monumentales hallados en las termas del foro de Carthago Nova. ZPE, 199, 243-253.

García León, J., García Marín, A., Torres Picazo, M. y Corbalán Hernández, M. J. (2013). Análisis cartográfico de la evolución histórica de la laguna «Almarjal», Cartagena. Mapping, 160, 4-10.

García Lorca, S. y Giménez López, F. (2007). Una vivienda del siglo III a.C. en Cartagena. Mastia, 6, 105-122.

González Fernández, R., Belmonte Avilés, J. A. y Marín Marín, J. M. (2014). C. Cornelius C. F. Sedbal. Nuevo ejemplo de antroponimia fenicio-púnica en Carthago Nova. CuPAUAM, 40, 97-109. DOI: http://dx.doi.org/10.15366/ cupauam2014.40.007

González García, A. C., Noguera Celdrán, J. M., Belmonte Avilés, J. A., Rodríguez Antón, A., Ruiz Valderas, E., Madrid Balanza, M. J. y Bonnet Casciaro, J. (2015). Orientatio ad sidera: astronomía y paisaje urbano en Qart Hadašt/ Carthago Nova. Zephyrus, 75, 141-162. DOI: http://dx.doi. org/10.14201/zephyrus201575141162

Hoz García-Bellido, M. P. (2014). Inscripciones griegas de España y Portugal. Madrid: Real Academia de la Historia.

Madrid Balanza, M. J., Celdrán Beltrán, E. y Vidal Nieto, M. (2005). La Domus de Salvius. Una casa de época altomperial en la calle del Alto de Cartagena (PERI C A-4/Barrio Universitario. Mastia, 4, 117-152.

Martínez Andreu, M. (2004). La topografía de Carthago Nova. Estado de la cuestión. Mastia, 3, 11-30.

Mata, J. (2014). Crisis ciudadana a partir del siglo II en Hispania: un modelo teórico de causas y dinámicas aplicado al Conuentus Carthaginensis. Cuadernos de Arqueología de la Universidad de Navarra, 22, 219-251.

Meroño Molina, R. (2014). Urbanismo romano de Carthago Nova: condicionantes, características y sistemas de ejecución. Arqueología y territorio, 11, 97-112.

Murcia Muñoz, A. J., López Mondéjar, L. y Ramallo Asensio, S. (2013). El territorio de Carthago Nova entre los siglos II a.C. y II d.C. En J. L. Fiches, J. L., R. Plana-Mallart y V. Revilla Calvo (Coords.). Paysages ruraux et territoires dans les cités de l'Occident romain. Gallia et Hispania (pp.121-135). Montpellier: Presses Universitaires de la Méditerranée.

Noguera Celdrán, J. M. y Abascal Palazón, J. M. (2003). Fragmentos de epígrafes e inscripción con litterae aureae del foro y del Augusteum de Carthago Nova. Mastia, 2, 11-63.

Noguera Celdrán, J. M. y Madrid Balanza, M. J. (2013). Mármoles y marmorización arquitectónica en Nova Carthago: nuevas evidencias del Molinete. En V. García-Entero (Ed.). El marmor en Hispania. Explotación, uso y difusión en época romana (pp. 229-252). Madrid: Universidad Nacional de Educación a Distancia.
Noguera Celdrán, J. M. y Madrid Balanza, M. J. (2014). Carthago Nova: Fases e hitos de monumentalización urbana y arquitectónica (siglos III a.C.-III d.C.). Espacio, Tiempo y Forma, 7, 13-60. DOI: http://dx.doi.org/10.5944/ etfi.7.2014.15668

Noguera Celdrán, J. M. y Madrid Balanza, M. J. (Coords.) (2009). Arx Hasdrubalis. La ciudad reencontrada. Arqueología en el cerro del Molinete. Cartagena: CARM.

Noguera Celdrán, J. M., Cánovas Alcaraz, A., Madrid Balanza, M. J. y Martínez Peris, I. (2016). Barrio del Foro Romano, Molinete, Cartagena. Proyecto integral de recuperación y conservación. Cartagena: Consorcio Cartagena Puerto de Culturas.

Noguera Celdrán, J. M., Soler Huertas, B., Madrid Balanza, M. J., Vizcaíno Sánchez, J. (2009). El foro de Carthago Nova. Estado de la cuestión. En J.M. Noguera (Ed.). Fora Hispaniae. Paisaje urbano, arquitectura, programas decorativos y culto imperial en los foros de las ciudades hispanorromanas (pp. 217-302). Murcia: CARM.

Plinio el Viejo (2002). Historia Natural. Madrid: Cátedra.

Polibio (1983). Historias. Libros V-XV. Madrid: Gredos.

Quevedo Sánchez, A. (2013). Contextos cerámicos y transformaciones urbanas en Carthago Nova: de Marco Aurelio a Diocleciano. (Tesis doctoral). Universidad de Murcia. Murcia.

Quevedo Sánchez, A. y Ramallo Asensio, S. (2015). La dinámica evolutiva de Carthago Nova entre los siglos II y III. En L. Brassous, L. y A. Quevedo (Eds.). Urbanisme civique en temps de crise. Les espaces publics d'Hispanie et de l'Occident romain entre le IIe et le IVe siècle (pp. 161-177). Madrid: Casa de Velázquez.

Ramallo, Asensio S. (2004). Decoración arquitectónica, edilicia y desarrollo monumental en Carthago Nova. En S. Ramallo Asensio (Ed.). La decoración arquitectónica en las ciudades romanas de Occidente (pp. 153-218). Murcia: Universidad de Murcia.

Ramallo Asensio, S. (2010-2011). Nuevos testimonios epigráficos sobre movilidad de población en Carthago Nova. Anales de Arqueología Cordobesa, 21-22, 315-330.

Ramallo Asensio, S. (2011). Carthago Nova. Puerto Mediterráneo de Hispania. Murcia: Fundación Cajamurcia.

Ramallo Asensio, S. (2015). Nuevos restos epigráficos del teatro de Cartagena. En J. García Sánchez, I. Mañas Romero y F. Salcedo Garcés, Navigare necesse est: estudios en homenaje a José María Luzón Nogué (pp. 529-541). Madrid: Universidad Complutense.

Ramallo Asensio, S. y Murcia Muñoz, A. J. (2010). Aqua et lacus en Carthago Nova: aportaciones al estudio del aprovisionamiento hídrico en época romana. ZPE, 172, 249-258.

Ramallo Asensio, S. y Ruiz Valderas, E. (1994). Un edículo republicano dedicado a Atargatis en Carthago Nova. AEs$p A, 67,79-102$.

Ramallo Asensio, S. y Ruiz Valderas, E. (1998). El teatro romano de Carthago Nova. Murcia: Fundación Cajamurcia. 
Ramallo Asensio, S., Fernández Díaz, A., Madrid Balanza, M. J. y Ruiz Valderas, E. (2008). Carthago Nova en los dos últimos siglos de la república: una aproximación desde el registro arqueológico. En J. Uroz Sáez, J. M. Noguera Celdrán y F. Coarelli (Coords.). Iberia e Italia: modelos romanos de integración territorial (pp. 573-604). Murcia: Tabularium.

Ramallo Asensio, S., Murcia Muñoz, A. J. y Vizcaíno Sánchez, J. (2010). Carthago Nova y su espacio suburbano. Dinámicas de ocupación en la periferia de la Urbs. En D. Vaquerizo Gil (Ed.). Las Áreas Suburbanas en la Ciudad Histórica. Topografia, usos y función (pp. 211-254). Córdoba: Universidad de Córdoba

Ramallo Asensio, S., Ruiz Valderas, E., Murcia Muñoz, A. J., Guillermo Martínez, M. (2013). La secuencia Históricoarqueológica del cerro de la Concepción a través del material cerámico: introducción al volumen. AnMurcia, 29, $11-22$.

Soler Huertas, B. (2005a). Hacia una sistematización cronológica sobre el empleo del marmor y su comercialización en Carthago Nova. Mastia, 4, 29-64.

Soler Huertas, B. (2005b). El travertino rojo de Mula (Murcia). Definición de un mármol local. Verdolay, 9, 141-164.
Soler Huertas, B. (2008). Marmora de importación y otros materiales pétreos de origen local en Carthago Nova: Explotación, comercio y función durante los periodos tardorrepublicano y Augusteo. En J. Uroz Sáez, J. M. Noguera Celdrán y F. Coarelli (Coords.). Iberia e Italia: modelos romanos de integración territorial (pp. 711-726). Murcia: Tabularium.

Soler Huertas, B., Antolinos Marín, J. A., Noguera Celdrán, J. M. y Alias Linares, A. (2012). Producción, aprovisionamiento y empleo de materiales constructivos en Carthago Nova. En J. Bonetto (Ed.). Las Canteras en el mundo antiguo: sistemas de explotación y procesos productivos. Actas del congreso de Padova, 22-24 de noviembre de 2012 (pp. 285-311). Mérida: Consejo Superior de Investigaciones Científicas.

Tito Livio (1990). Historia de Roma desde su fundación. Libros XXVI-XXX. Madrid: Gredos.

Uroz Rodríguez, H. (2003). La importancia de los cultos salutíferos y el cosmopolitismo en la Carthago Nova tardorrepublicana y altoimperial. Eutopia, 1-2, 7-33.

Vizcaíno Sánchez, J. (2002). Reutilización de material en la edilicia tardoantigua. El caso de Cartagena. Mastia, 1, 207-220. 